\title{
The effect of BC on aerosol-boundary layer feedback: potential implications for urban pollution episodes
}

\author{
Jessica Slater ${ }^{1,2}$, Hugh Coe ${ }^{1}$, Gordon McFiggans ${ }^{1}$, Juha Tonttila ${ }^{3}$, and Sami Romakkaniemi ${ }^{3}$ \\ ${ }^{1}$ Stockholm Environment Institute, Department of Environment and Geography, University of York, York, UK \\ ${ }^{2}$ Centre for Atmospheric Science, School of Earth and Environmental Sciences, \\ University of Manchester, Manchester, UK \\ ${ }^{3}$ Finnish Meteorological Institute, Atmospheric Research Centre of Eastern Finland, Kuopio, Finland
}

Correspondence: Jessica Slater (jessicaslater76@gmail.com)

Received: 20 February 2021 - Discussion started: 7 April 2021

Revised: 29 November 2021 - Accepted: 12 December 2021 - Published: 3 March 2022

\begin{abstract}
Beijing suffers from poor air quality, particularly during wintertime haze episodes when concentrations of $\mathrm{PM}_{2.5}$ (particulate matter with a diameter $<2.5 \mu \mathrm{m}$ ) can peak at $>400 \mu \mathrm{g} \mathrm{m}{ }^{-3}$. Black carbon (BC), an aerosol which strongly absorbs solar radiation, can make up to $10 \%$ of $\mathrm{PM}_{2.5}$ in Beijing. $\mathrm{BC}$ is of interest due to its climatic and health impacts. BC has also been found to impact planetary boundary layer (PBL) meteorology. Through interacting with radiation and altering the thermal profile of the lower atmosphere, $\mathrm{BC}$ can either suppress or enhance PBL development depending on the properties and altitude of the BC layer.

Previous research assessing the impact of BC on PBL meteorology has been investigated through the use of regional models, which are limited both by resolution and the chosen boundary layer schemes. In this work, we apply a high-resolution model (UCLALES-SALSA) that couples an aerosol and radiative transfer model with large-eddy simulation (LES) to quantify the impact of BC at different altitudes on PBL dynamics using conditions from a specific haze episode which occurred from 1-4 December 2016 in Beijing. Results presented in this paper quantify the heating rate of BC at various altitudes to be between 0.01 and $0.016 \mathrm{~K} / \mathrm{h} \mathrm{per} \mu \mathrm{g} / \mathrm{m}^{3}$ of $\mathrm{BC}$, increasing with altitude but decreasing around PBL top. Through utilising a high-resolution model which explicitly calculates turbulent dynamics, this paper showcases the impact of $\mathrm{BC}$ on PBL dynamics both within and above the PBL. These results show that BC within the PBL increases maximum PBL height by $0.4 \%$ but that the same loading of $\mathrm{BC}$ above the PBL can suppress PBL height by $6.5 \%$. Furthermore, when BC is present throughout the column, the impact of BC suppressing PBL development is further maximised, with BC causing a $17 \%$ decrease in maximum PBL height compared to only scattering aerosols. Assessing the impact of these opposite effects, in this paper, we present a mechanism through which BC may play a prominent role in the intensity and longevity of Beijing's pollution episodes.
\end{abstract}

\section{Introduction}

Beijing, a megacity situated in the North China Plain, experiences extremely poor air quality. Typically in Beijing wintertime, heavy pollution episodes termed "haze" envelop the city and concentrations of $\mathrm{PM}_{2.5}$ (particulate matter with a diameter $<2.5 \mu \mathrm{m}$ ) frequently exceed the recommended World Health Organization exposure limits $\left(10 \mu \mathrm{g} / \mathrm{m}^{3}\right.$ annual average and $25 \mu \mathrm{g} / \mathrm{m}^{3} 24 \mathrm{~h}$ average) (WHO, 2006). Poor air quality has been linked to various respiratory and cardiovas- cular diseases as well as neurodegenerative diseases such as Parkinson's and dementia (Yang et al., 2013; Lelieveld et al., 2015; Chen et al., 2017). Improving air quality is therefore a public health priority for the Chinese government. However, despite policy interventions which have improved annual average air quality in Beijing over the past decade, heavy pollution episodes are still a major issue (Chan and Yao, 2008). Black carbon (BC), primarily emitted through incomplete combustion, is a strongly absorbing aerosol present in high 
concentrations in Chinese megacities (Fu and Chen, 2016). In Beijing, $\mathrm{BC}$ can contribute up to $10 \%$ of total particulate matter (PM) during polluted periods (Liu et al., 2016). Major sources of BC in Beijing are traffic, biomass burning and coal combustion for both residential and industrial use (Streets et al., 2001).

$\mathrm{BC}$ is of interest globally due to its climatic and health impacts. As a short-lived climate pollutant which strongly absorbs radiation across the shortwave (SW) spectrum, BC can directly cause atmospheric warming and is considered to be the largest anthropogenic contributor to global warming after carbon dioxide $\left(\mathrm{CO}_{2}\right)$ (Bond et al., 2013). Furthermore, due to its relatively short lifetime in the atmosphere (days) compared to $\mathrm{CO}_{2}$ (years), reducing concentrations of $\mathrm{BC}$ in the atmosphere could have a rapid impact on global temperatures, with the added benefit of improving air quality for human health. The global direct radiative forcing of $\mathrm{BC}$ at top of atmosphere (TOA) is estimated to be between $0.2-$ $1.2 \mathrm{~W} / \mathrm{m}^{2}$ (Ramanathan and Carmichael, 2008; Bond et al., 2013). Calculating the global direct radiative forcing effect (DRE) of BC is complicated by its spatial heterogeneity, with a higher effect (up to $10 \mathrm{~W} / \mathrm{m}^{2}$ ) in heavily polluted urban areas where $\mathrm{BC}$ concentrations are significantly higher (Ferrero et al., 2014; Li and Han, 2016). Furthermore, the DRE of BC is significantly affected by its source, vertical distribution, atmospheric conditions and its mixing with other components of PM within the atmosphere, which can alter its optical properties (Zhao et al., 2020). Consequently, understanding the properties and interactions of $\mathrm{BC}$ in the atmosphere is important for both air quality and climate.

Through absorbing radiation and altering the thermal profile of the atmosphere, $\mathrm{BC}$ may play an important role in the enhancement of pollution episodes via the aerosol-planetary boundary layer (PBL) feedback mechanism. The mechanism can be described as follows: scattering and absorbing aerosol particles interact with solar radiation to reduce the amount of shortwave radiation (SWR) reaching the surface. The consequent reduction in SWR at the surface results in reduced buoyancy of the surface air and can impact the development of the PBL throughout the day. Specifically, aerosols suppress the development of the PBL, which leads to the aerosols themselves being more concentrated at the surface and thus having stronger interactions with SWR. The effect of BC on PBL development and the aerosol-PBL mechanism is highly dependent on the properties of $\mathrm{BC}$ as well as the altitude of the $\mathrm{BC}$ layer. In theory, concentrations of $\mathrm{BC}$ at the surface will warm the lower layer, promoting buoyant turbulence and decreasing atmospheric stability, while a layer of $\mathrm{BC}$ aloft is thought to further enhance any existing temperature inversions, increasing temperatures aloft and decreasing them at the surface leading to atmospheric stabilisation (Fig. 1). Upper level BC (BC above the PBL) is also believed to have a higher heating efficiency due to a combination of the lower density of air and higher incident radiation flux at higher altitudes, allowing for $\mathrm{BC}$ particles to absorb more ra- diation and heat air at a higher rate. This suggests that even low concentrations of $\mathrm{BC}$ at high altitudes may lead to atmospheric stabilisation. This is considered to be the so-called "dome effect" of BC (Ding et al., 2016; Gao et al., 2015; Petäjä et al., 2016; Wang et al., 2018; Zou et al., 2017).

The impact of BC on the aerosol-PBL feedback is dependent on several factors, including the altitude of the BC layer, its concentration and mixing state. Ding et al. (2016) found that $\mathrm{BC}$ enhanced haze episodes through warming the air above the PBL and enhancing stratification of the boundary layer. Wang et al. (2018) found that surface BC promoted PBL development through warming but that this effect was negated by the stronger interactions of $\mathrm{BC}$ aloft, which suppressed PBL growth. Ding et al. (2016) first showed the importance of the $\mathrm{BC}$ dome effect through conducting simulations of three megacities in eastern China and changing the level of aerosol feedback. Through this, they directly characterised the feedback effect of BC compared to that of other aerosols. Their results showed that a maximum change in SWR due to BC occurred at the top of the PBL (around $400 \mathrm{~m}$ in this case) and that $\mathrm{BC}$ at this altitude was primarily responsible for the large suppression in PBL height, despite only making up $30 \%$ of the column BC concentration. Furthermore, BC reduces downwelling surface SW radiation, leading to surface cooling and contributing up to $50 \%$ of the total aerosol reduction in surface fluxes. In a 1D modelling study, Wang et al. (2018) found that BC aloft was essential in the suppression of PBL height, with surface BC increasing both turbulence and PBL height. Furthermore, they found that a $\mathrm{BC}$ layer close to the PBL top and internal mixing of BC with scattering aerosols (sulfate $\left(\mathrm{SO}_{4}^{2-}\right)$, nitrate $\left(\mathrm{NO}_{3}^{-}\right)$and ammonium $\left(\mathrm{NH}_{4}^{+}\right)$) significantly enhanced the dome effect of $\mathrm{BC}$, leading to a reduction in PBL height of $15 \%$. BC is thought to exist above the PBL in Beijing due to aerosols being transported from surrounding regions by synoptic-scale winds and through aerosols remaining in the residual layer overnight after being mixed through the PBL in the previous day (Wang et al., 2016; Zhao et al., 2020).

Thus far, methods of examining the impact of $\mathrm{BC}$ on the aerosol-PBL feedback in Beijing have been with observational or regional modelling studies, with specific radiative transfer models used to calculate direct radiative effects (Ding et al., 2016, 2017; Wang et al., 2018; Zhao et al., 2020). Large-eddy simulation (LES) models directly simulate turbulent motion and PBL development without the parameterisation of boundary layer processes, which is necessary in regional models such as WRF-CHEM. This gives them a significant advantage in understanding and quantifying perturbations to the PBL. Previously, LES models have been used to examine the effect of absorbing aerosol layers on the development of stratocumulus and cumulus clouds. Herbert et al. (2020) examined the effect of an absorbing layer on stratocumulus clouds and thus the PBL development and rates of entrainment, finding a significant reduction in the entrainment rate the closer the absorbing layer was 


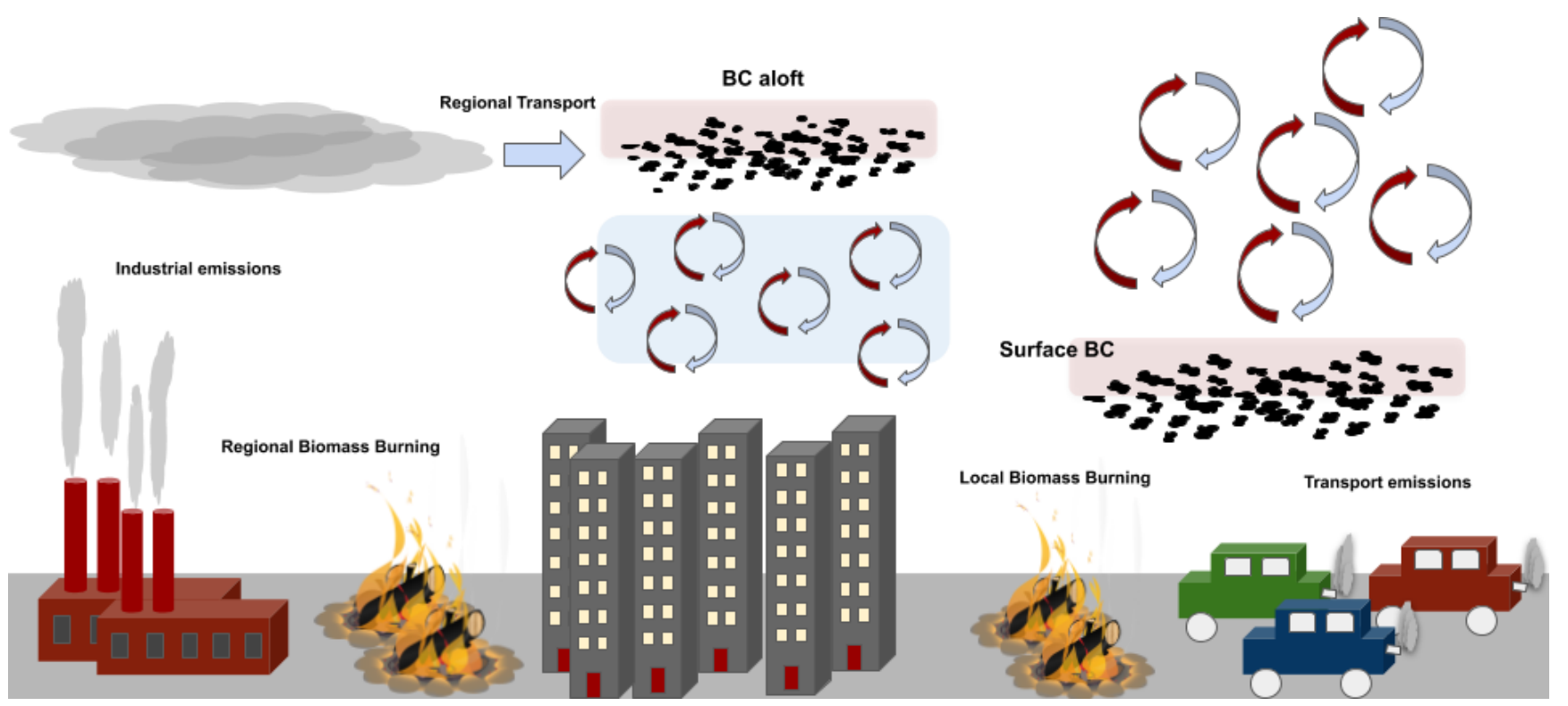

Figure 1. Schematic showing some of the sources of BC in Beijing, which include industrial emissions, regional and local biomass burning and emissions from transport, as well as outlining the main concepts presented in this paper of the influence of $\mathrm{BC}$ aloft and $\mathrm{BC}$ within the PBL on PBL dynamics.

to cloud top. Related to dissipation of radiation fog, Maalick et al. (2016) found that in polluted conditions, BC has a warming effect close to the fog top, and $\mathrm{BC}$ enhances fog dissipation due to absorption of solar radiation. However, if the increase in $\mathrm{BC}$ concentration is accompanied with an increase in cloud condensation nuclei $(\mathrm{CCN})$ and thus fog droplet concentration, the $\mathrm{CCN}$ effect increasing fog lifetime is much stronger than the contrasting $\mathrm{BC}$ effect which works to shorten fog lifetime.

In this work, we use the coupled LES-aerosol-radiation model (UCLALES-SALSA), which has previously been set up and tested in Beijing to examine the impact of $\mathrm{BC}$ on aerosol-PBL interactions and the implication on Beijing haze episodes (Slater et al., 2020, 2021). The high resolution of LES models and their ability to calculate turbulent fluxes and perturbations thereof allows for isolation and quantification of the different factors impacting the dome effect of BC. We use meteorological conditions from $2 \mathrm{~d}$ in the middle of a haze episode (2 and 3 December 2016), where a strong temperature inversion and shallow PBL already exist due to the convergence of cold northerly air masses with southerly warm air masses (Wang et al., 2019). Specifically, this work investigates the dome effect of $\mathrm{BC}$, through isolating the impact of BC both above and within the PBL and the impact on PBL dynamics. This paper showcases a series of idealised simulations. It is worth noting that in all simulations there is no surface heterogeneity or changes in vertical structure across the model field. Due to the lack of heterogeneity across the model field, all results presented and plots shown are horizontal domain averages to explain the driving processes as a function of time. This paper is set out as follows. Section 2 describes model setup, including experimental setup for the different sensitivities examined, while Sect. 4 briefly discusses the overall results and their implications in more detail.

\section{Methods}

\subsection{Model description}

The model used in this study is UCLALES-SALSA, which is a large-eddy simulation model (UCLALES) fully coupled to the sectional aerosol model (SALSA). UCLALES-SALSA has been used to examine the impact of aerosols on stratocumulus clouds, radiation fog and cloud seeding and to examine the aerosol-PBL feedback in Beijing (Tonttila et al., 2017; Slater et al., 2020; Tonttila et al., 2021; Slater et al., 2021). LES models resolve the three-dimensional turbulent field of wind and scalar concentrations, directly resolve most of the energy and parameterise only the smallest scale eddies. UCLALES uses the Smagorinsky-Lilly subgrid model, with leapfrog time stepping used for advection of momentum variables and forward time stepping for advection of scalar variables, based on fourth-order differential equations. Boundary conditions are periodic in both horizontal directions and fixed in the vertical. The surface scheme for moisture and heat is based on a coupled soil moisture and surface temperature scheme by Ács et al. (1991), which explicitly calculates surface temperature and sensible and latent heat fluxes. The surface scheme used in this case has been adapted and tested for the urban environment of Beijing and the setup which includes the addition of a diurnal anthropogenic heat flux $\left(Q_{\mathrm{f}}\right)$ 
and alterations to the surface heat capacity value as detailed in Slater et al. (2020).

SALSA is a sectional aerosol model which has been fully coupled to both UCLALES and the climate model ECHAM (Kokkola et al., 2008, 2018). SALSA bins aerosol particles according to size, with three bins for aerosol particles in the nucleation mode (diameter between 3 and $50 \mathrm{~nm}$ ) and two sets of seven parallel size bins for aerosol particles in the Aitken, accumulation and course modes (diameters between $50 \mathrm{~nm}$ and $10 \mu \mathrm{m}$ ), which allow for aerosols to be both internally and externally mixed. In the results set out here, we assume all particles to be internally mixed. Processes including deposition of aerosols, semi-volatile condensation, nucleation and emissions are switched off, but aerosol coagulation and water condensation on aerosol particles are turned on. For these simulations, organic carbon (OC), $\mathrm{SO}_{4}^{2-}, \mathrm{NO}_{3}^{-}, \mathrm{BC}$ and $\mathrm{NH}_{4}^{+}$are included. We use the same size distribution for all simulations (Table 1), and composition is varied slightly to examine the impact of fractional composition changes of BC (Table 2).

To calculate aerosol-radiation interactions, SALSA uses a four-stream radiative transfer scheme based on the work by Fu and Liou (1993). This scheme is fully coupled to UCLALES to allow for feedback on turbulent dynamics and is a four-stream method integrating over $6 \mathrm{SW}$ bands and 12 LW bands. To account for the impact of aerosol size on aerosol-radiation interactions, we use pre-computed constant refractive indices and use lookup tables for the aerosolextinction cross section, asymmetry parameter and singlescattering albedo, which are calculated as a function of the size parameter $\left(\alpha=\frac{D_{\mathrm{p}}}{\lambda}\right)$, where $D_{\mathrm{p}}$ is the particle diameter, and $\lambda$ is the wavelength of light. In this work we set all imaginary parts of the refractive indices in the SW to zero apart from that of $\mathrm{BC}$, which is set to values according to Bond and Bergstrom (2006). This allows us to consider BC as the only absorbing aerosol. SALSA treats internal mixing for optical properties in a simple way, through volume averaging of the complex refractive index of each component in each particle. Optical properties of the entire particle are calculated from the average refractive index of the particle according to volume as detailed in Jacobson (2005). Therefore, the potential of scattering aerosols to enhance absorption of BC through the "lensing effect" is not considered here.

\subsection{Experimental setup}

The work presented here is divided into three sections, and the specific setup for each sensitivity is detailed in the appropriate section. We perform simulations for 2 and 3 December 2016 in Beijing, varying the altitude of the aerosol layers and fractional composition. Initial meteorological conditions were taken from radiosonde profiles which are located at Beijing International Airport, with measurements being taken twice per day at 08:00 and 20:00 local time. Aerosol composition and size parameters were calculated based on ground-
Table 1. Size distribution input data - geometric mean diameter $\left(D_{\mathrm{g}}\right)$ and geometric standard deviation $\left(\sigma_{\mathrm{g}}\right)$.

\begin{tabular}{lrr}
\hline Parameter & Mode 1 & Mode 2 \\
\hline$D_{\mathrm{g}}(\mathrm{nm})$ & 22 & 121 \\
$\sigma_{\mathrm{g}}$ & 1.28 & 1.32 \\
\hline
\end{tabular}

Table 2. Volume fractional composition for BC and no BC simulations in all simulations.

\begin{tabular}{lrrrrr}
\hline & $\mathrm{SO}_{4}$ & $\mathrm{BC}$ & $\mathrm{OC}$ & $\mathrm{NO}_{3}$ & $\mathrm{NH}_{4}$ \\
\hline BC case & 0.1 & 0.1 & 0.45 & 0.25 & 0.1 \\
No BC case & 0.2 & 0.0 & 0.45 & 0.25 & 0.1 \\
\hline
\end{tabular}

based measurements taken at 08:00 on 3 December 2016 during the Air Pollution and Human Health (APHH) winter field campaign (Shi et al., 2019). The initial aerosol vertical profiles were estimated based on the gradient of boundary layer profiles. The model was set up at 08:00 LST and run for $12 \mathrm{~h}$ including $1 \mathrm{~h}$ spin-up time. The horizontal domain size was $5.4 \times 5.4 \mathrm{~km}^{2}$ with a resolution of $30 \mathrm{~m}$, and the model top was set to $1800 \mathrm{~m}$ with a vertical resolution of $10 \mathrm{~m}$. For all simulations, the initial size distribution is outlined in Table 1, while the fractional composition of the aerosol particles for $\mathrm{BC}$ and no BC simulations is detailed in Table 2. For all results, PBL top or maximum PBL height is taken as the height at which there is a maximum gradient in potential temperature $(\theta)$.

Individual case setups for the changing conditions examined in this paper are detailed in Sect. 2.2. Overall, three case study experiments with a total of 14 simulations were performed to examine the different impact of (1) aerosol loading at different altitudes both with and without the effect of BC (Case Aero_load), (2) different initial meteorological conditions (Case Met) and 3) changing concentrations of BC within the aerosol column (Case BC_load). Section 2.2.1 outlines the setup of simulations for the first case study (Case Aero_load), which examines the impact of varying the composition of aerosol layers at different altitudes to either include or not include BC. These six simulations are varied so that there are three different altitudes for an aerosol layer, and each layer either has a fractional composition of $10 \% \mathrm{BC}$ or no BC (Table 2). In these simulations, the aerosols are only present within the specified layer, with no aerosols present initially above or below the layer. Section 2.2.2 outlines the setup for the second case study (Case Met), which focuses on examining the effect of initial meteorological conditions on the impact of $\mathrm{BC}$ heating within the PBL on boundary layer. For these four simulations only, a surface aerosol layer is considered, and the initial meteorological conditions are either taken from the morning of 2 or 3 December 2016. Section 2.2.3 describes the setup for the third case study (Case 
BC_load) simulations, which examines the impact of varying the fraction of $\mathrm{BC}$ in different vertical layers for simulations where aerosols are present throughout the column.

\subsubsection{Case Aero_load}

To isolate the impact of $\mathrm{BC}$ and the altitude of the $\mathrm{BC}$ layer on the aerosol-PBL feedback, we performed sensitivity studies with meteorological conditions taken from measurements on the morning of 3 December 2016. In the simulations presented in this section, we varied the altitude of the aerosol layer as well as the fractional composition of the aerosols, to either have $\mathrm{BC}$ or no $\mathrm{BC}$ within the layer (Table 2). We included aerosol layers with identical mass mixing ratios within the PBL $(0-350 \mathrm{~m})$, at and above PBL top (500-950 m) and high aloft (700-1150 m), as shown in Fig. 2 (red, blue and cyan lines respectively). Maximum PBL height (top) was considered to be $510 \mathrm{~m}$ based on simulations performed on this day without aerosols. For all simulations in this section, total aerosol loading was kept constant, while the composition was varied as detailed in Table 2 and concentrations and altitudes of each of the aerosol layers as shown in Fig. 2.

Table 3 details the names and brief description of each of the simulations in this case. Figure 2 shows the vertical aerosol profiles for each of the simulations. Figure 2 a shows the variation in $\mathrm{BC}$ concentrations for the three simulations which include BC (solid lines), while the simulations without BC (dashed lines) have no BC through the whole layer. Figure $2 \mathrm{~b}$ shows the variation in $\mathrm{SO}_{4}^{2-}$ aerosol concentrations. As shown in Table 2 and Fig. 2c, for simulations without $\mathrm{BC}$, the initial aerosol concentrations are the same as the simulations with $\mathrm{BC}$, but the fractional composition is varied so that there is double the concentration of $\mathrm{SO}_{4}^{2-}$. Figure $2 \mathrm{c}$ shows the overall vertical variation in aerosol layers for the different simulations, where the $\mathrm{BC}$ and no $\mathrm{BC}$ simulations for each of the three different layers have the same aerosol vertical profiles.

\subsubsection{Case Met}

To examine how sensitive $\mathrm{BC}$ heating at the surface is to the initial meteorological conditions, particularly the strength of temperature inversions both in the morning and throughout the day, we included an aerosol layer with BC near the surface for simulations on 2 December and compared the results to simulations performed on 3 December. We then compared each simulation to a reference simulation, hereafter referred to as the base case, which did not include aerosol-radiation interactions. The differences in initial meteorological conditions are outlined in Fig. 3. On the 2 December, relative humidity is lower (Fig. 3b), while surface wind speeds are higher (Fig. 3c), and the total temperature inversion throughout the profile is weaker (Fig. 3a) than on 3 December. Furthermore, there is a shallow layer with a sharp temperature inversion at the surface in the 2 December initial profile. However, the free-tropospheric lapse rates (above $1000 \mathrm{~m}$ ) for 3 December are higher than on 2 December, indicating a higher degree of stability on this day. The aim of this case study was to examine the influence of these initial conditions on $\mathrm{BC}$ heating within the PBL and the associated impact on PBL dynamics.

For these simulations, the aerosol profiles for each day were kept the same, so the only variable was the different initial meteorological conditions. The included aerosol profiles are the same as for case Aero_load_BCsurf in Sect. 2.2.1 (solid red lines in Fig. 2).

\subsubsection{Case BC_load}

Simulations in this setup examined the impact of changing the fractional composition of BC in different aerosol layers. The total aerosol loading in the column was kept constant in each simulation, but the composition in different layers was varied as is detailed for BC and no BC cases in Table 2. This setup was done as a proxy to examine the idea of reducing $\mathrm{BC}$ at the surface without tackling regional emissions of $\mathrm{BC}$ which may get transported from surrounding areas, leading to high concentrations above the PBL. Table 5 outlines a brief description of variations used in each simulation for the BC_load case.

The setup here uses meteorological conditions from 3 December 2016 as outlined in Sect. 2.2.1 but includes aerosols throughout the column, rather than just in specific layers. Details of the variation in $\mathrm{BC}$ concentrations are outlined in Fig. 4 and include BC throughout the column (red lines), BC above $500 \mathrm{~m}$ (blue lines), BC above $1000 \mathrm{~m}$ (cyan lines) and no $\mathrm{BC}$ (green lines). Each of the individual simulations and the corresponding names of each of the simulations are detailed in Table 5. As in the setup described in Sect. 2.2.1, the aerosol loading throughout the column is the same with changes in composition for the $\mathrm{BC}$ and no $\mathrm{BC}$ cases, as detailed in Table 1. Figure 4a shows the variation in BC loading, Fig. $4 \mathrm{~b}$ shows the variation in $\mathrm{SO}_{4}^{2-}$ loading and Fig. $4 \mathrm{c}$ shows total aerosol vertical profiles for all simulations.

\section{Results}

The results here are separated into three sections based on the experimental setup outlined in Sect. 2.2.1-2.2.3. Section 3.1 outlines results from Case Aero_load simulations performed as outlined in Sect. 2.2.1 for vertically varied aerosol layers, and Sect. 3.2 shows results from Case Met simulations, looking at the effect of initial meteorological conditions as described in the setup in Sect. 2.2.2. Finally, Sect. 3.3 showcases results from case BC_load simulations, which examines the effect of varying BC loading in different vertical layers, as described in the setup in Sect. 2.2.3. 
Table 3. Table detailing the outline of each of the six simulations for the first case study (Case Aero_load).

\begin{tabular}{ll}
\hline Case name & Description \\
\hline Aero_load_BCsurf & Aerosols (including BC) are only included initially in a layer between 0-350 m \\
Aero_load_noBCsurf & Aerosols (not including BC) are only included initially in a layer from 0-350 m \\
Aero_load_BC500 & Aerosols (including BC) are only included initially in a layer from 500-950 m \\
Aero_load_noBC500 & Aerosols (not including BC) are only included initially in a layer from 500-950 m \\
Aero_load_BC700 & Aerosols (including BC) are only included initially in a layer from 700-1150 m \\
Aero_load_noBC700 & Aerosols (including BC) are only included initially in a layer from 700-1150 m \\
\hline
\end{tabular}

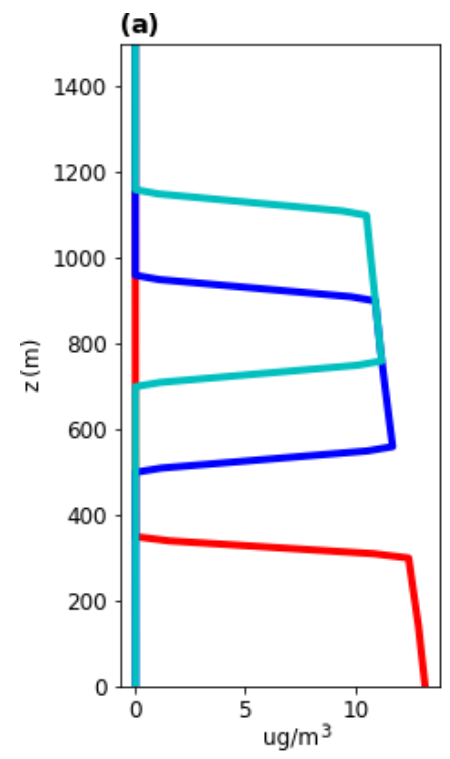

(b)

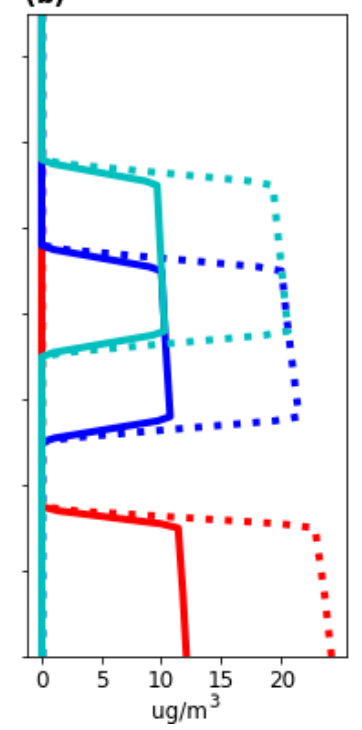

(c)

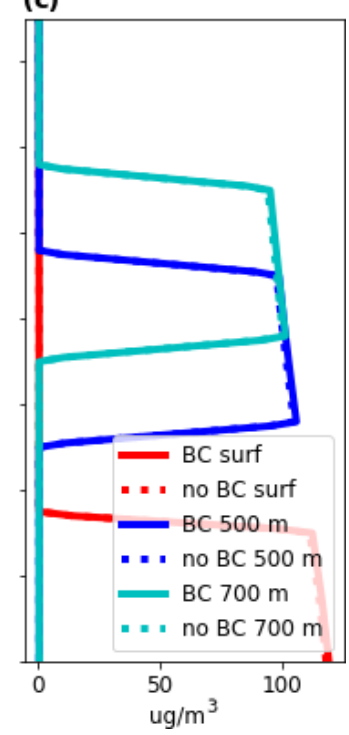

Figure 2. Initial mass concentrations of (a) $\mathrm{BC}$, (b) $\mathrm{SO}_{4}^{2-}$ and (c) total aerosol concentrations for simulations in case 1. Different heights were chosen for the initial aerosol layers, which were 0-350 m (red lines), 500-950 m (blue lines) and 700-1150 m (cyan lines). Simulations which included BC are depicted by solid lines, and those without are dashed lines.

\subsection{Case Aero_load - vertically varied aerosol layers}

Results from varying the height of aerosol layers in the column, with and without BC aerosols, show that at all altitudes, $\mathrm{BC}$ in the aerosol layer has more impact on PBL dynamics than the effect of scattering aerosols alone (no BC simulations) (Table 6). Specifically, simulations without BC have a small effect on surface temperature, sensible heat flux and PBL height. At the surface (Aero_load_BCsurf), BC decreases downwelling surface SWR by $4 \%$ compared to including only scattering aerosols (Aero_load_noBCsurf), due to the increased absorption caused by increasing the $\mathrm{BC}$ fraction. This decreases maximum surface sensible heat flux (SHF) by $11 \%$ and slightly decreases surface temperature by $0.02 \%$. However, BC absorption of SWR at this altitude causes warming of the air layer above the surface (Aero_load_BCsurf), leading to a slight increase in air temperature at $10 \mathrm{~m}(0.07 \%)$ and PBL height $(0.4 \%)$ compared to the Aero_load_noBCsurf simulation (Table 6).

For further analysis, we calculated SW heating rate at time $(t)$ by BC as the change in SW radiative flux $(\downarrow S W-\uparrow S W)$, divided by the specific heat capacity of air $\left(C_{\mathrm{p}}\right)$ and multiplied by the density of air $(\rho)$ as in Eq. (1). Each time step $(t+\Delta t)$ here is $2 \mathrm{~min}$.

$$
\begin{aligned}
& \text { SW heating rate }_{(t)} \\
& =\frac{(\downarrow \mathrm{SW}-\uparrow \mathrm{SW})_{(t+\Delta t)}-(\downarrow \mathrm{SW}-\uparrow \mathrm{SW})_{(t)}}{C_{\mathrm{p}} \cdot \rho}
\end{aligned}
$$

We calculate that the heating rate of $\mathrm{BC}$ varied between $0.1-0.2 \mathrm{~K} / \mathrm{h}$, which could lead to a maximum heating of the PBL throughout the day in wintertime Beijing of 1.6-2 K. If the temperature inversion during the day was small $(1-3 \mathrm{~K})$, this additional heating by $\mathrm{BC}$ within the PBL and at PBL top could break the temperature inversion at PBL top and increase PBL height. However, under a strong temperature inversion as on 3 December, this heating within the PBL was not strong enough to reduce the temperature inversion fully, and so there was a very small increase in PBL height. Consequently, BC heating within the PBL in this case only resulted in a very small $(0.4 \%)$ increase in PBL height (Table 6). The 
Table 4. Table detailing the outline of each of the four simulations for the second case study focusing on the impact of initial meteorological conditions (Case Met).

\begin{tabular}{ll}
\hline Case name & Description \\
\hline Met_0212_noaero & $\begin{array}{l}\text { Initial meteorological conditions taken from the morning of 02/12/2016 } \\
\text { - no aerosols included in the simulation }\end{array}$ \\
\hline Met_0212_aero & $\begin{array}{l}\text { Initial meteorological conditions taken from the morning of 02/12/2016 } \\
\text { - aerosols including BC are only included below 400 m }\end{array}$ \\
\hline Met_0312_noaero & $\begin{array}{l}\text { Initial meteorological conditions taken from the morning of 02/12/2016 } \\
\text { - no aerosols included in the simulation }\end{array}$ \\
\hline Met_0312_aero & $\begin{array}{l}\text { Initial meteorological conditions taken from the morning of 03/12/2016 } \\
\text { - aerosols including BC are only included below 400 } \mathrm{m}\end{array}$ \\
\hline
\end{tabular}
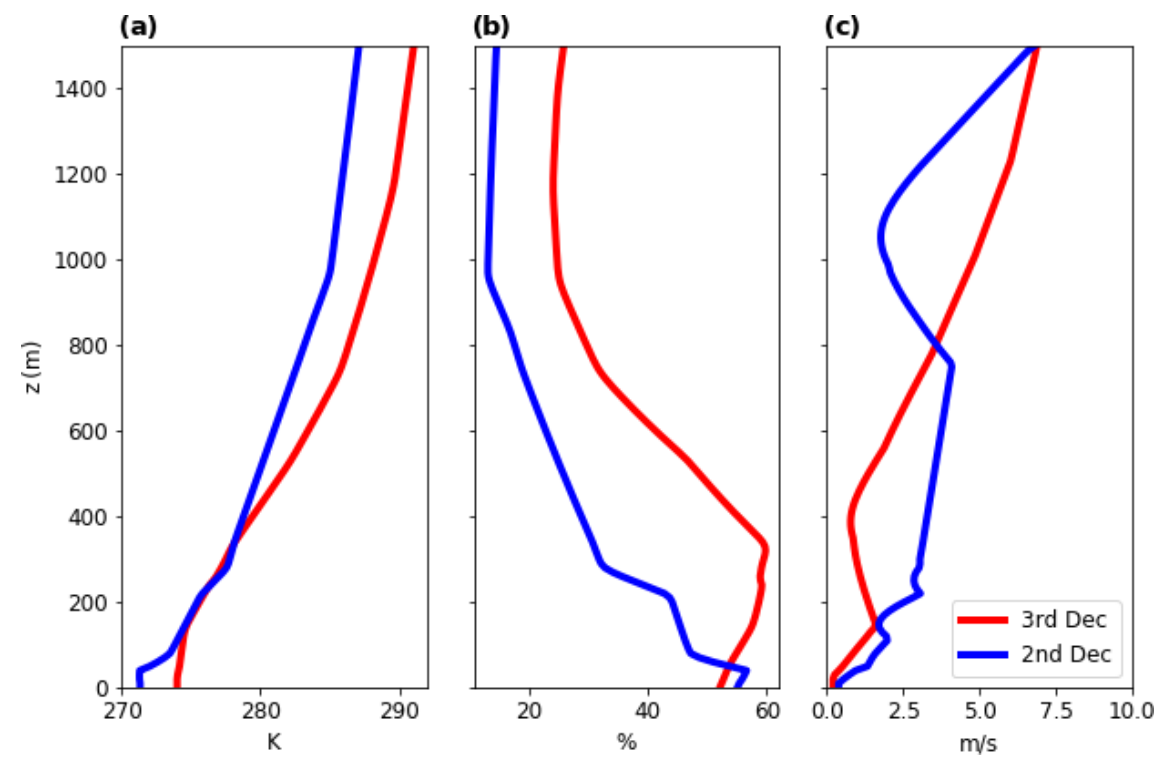

Figure 3. (a) Potential temperature, (b) relative humidity and (c) wind speed profiles at 09:00 for 3 December (blue) and 2 December (red).

Table 5. Table detailing the outline of each of the four simulations for the third case study focusing on the impact of changing BC loading in different aerosol layers (Case BC_load).

\begin{tabular}{ll}
\hline Case name & Description \\
\hline BC_load_noBC & No BC included at all altitudes \\
BC_load_500 & BC included above $500 \mathrm{~m}$ only \\
BC_load_1000 & BC included above $1000 \mathrm{~m}$ only \\
BC_load_full & BC included at all altitudes in the profile \\
\hline
\end{tabular}

strength of the temperature inversion and the growth of the PBL throughout the day are impacted by the synoptic-scale meteorological conditions. Furthermore, the low albedo (0.2) and high heat capacity of the underlying surface, typical of an urban environment, mean that $\mathrm{BC}$ at the surface will have a lower impact than studies which have examined the effect of polluted environments over high albedo surfaces, for example, clouds or rural environments (Wang et al., 2018).

Figure 5 outlines the changes in SW downwelling and upwelling radiation as well as the SW heating rate due to the presence of $\mathrm{BC}$ in the aerosol layers for all three simulations which include BC (Aero_load_BC700, Aero_load_BC500 and Aero_load_BCsurf from left to right respectively). In the case of BC aloft (Aero_load_BC700) there is a reduction in downwelling SW radiation both within and under the aerosol layer (Fig. 5d) and a reduction in SW upwelling radiation (Fig. $5 \mathrm{~g}$ ) through the layer due to absorption. The reduction in downwelling radiation beneath the aerosol layer leads to a cooling effect due to less available radiation heating the air. Meanwhile the absorption of SW radiation in the aerosol layer causes heating. This results in a change in the thermal profile of the atmosphere; it enhances the temperature inversion and decreases maximum PBL height and atmospheric temperature (Table 6). 

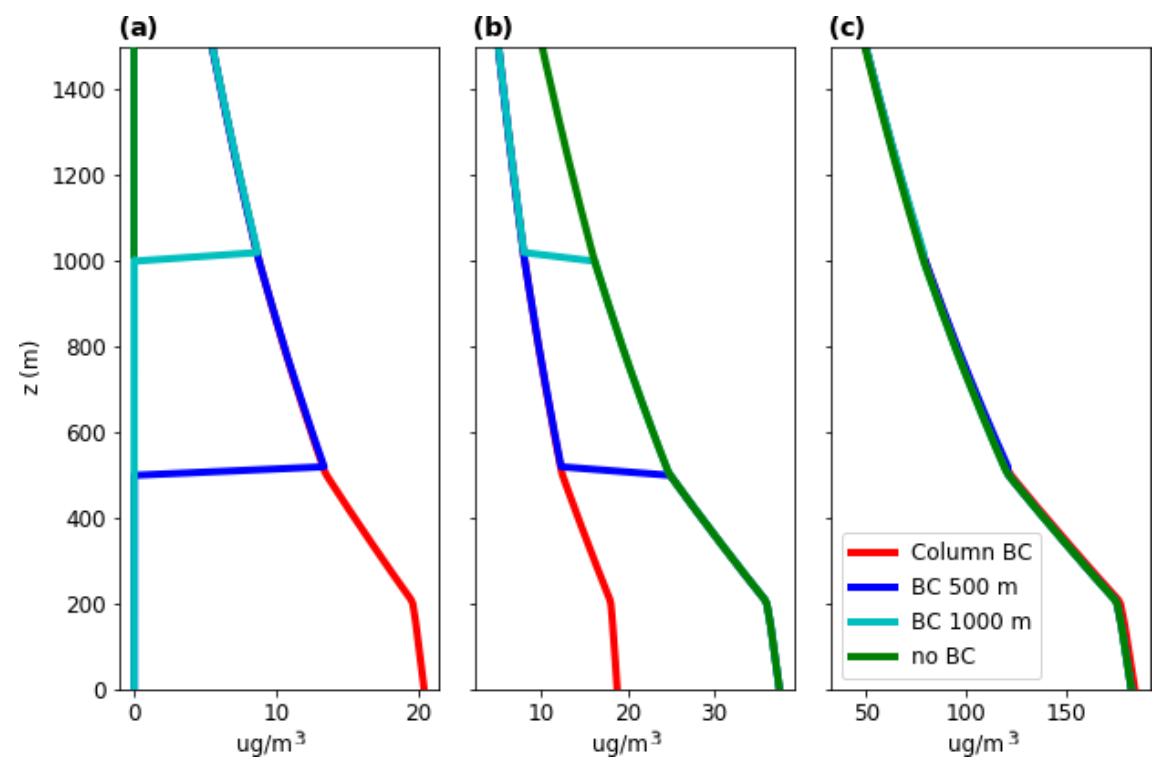

Figure 4. Initial mass concentrations of (a) $\mathrm{BC}$, (b) $\mathrm{SO}_{4}^{2-}$ and (c) total aerosol for each of the experiments outlined. For simulations with the same aerosol concentration but varying composition across the column to have $\mathrm{BC}$ through the column (red), BC above $500 \mathrm{~m}$ (blue), $\mathrm{BC}$ above $100 \mathrm{~m}$ (cyan) and no BC throughout the column (green).

Table 6. Maximum sensible heat flux (SHF), planetary boundary layer (PBL) height (taken as the height with the largest gradient in $\theta$ ), surface temperature $(T)$, downwelling shortwave radiation ( $\downarrow$ SWR) at the surface, upwelling shortwave radiation ( $\uparrow$ SWR) at model top $(1800 \mathrm{~m})$ and air temperature $(T)$ at $10 \mathrm{~m}$. Values are the maximum between 12:00 and 16:00 local standard time (LST).

\begin{tabular}{lrrrrrr}
\hline & $\begin{array}{r}\text { SHF } \\
\left(\mathrm{W} / \mathrm{m}^{2}\right)\end{array}$ & $\begin{array}{r}\text { PBL height } \\
(\mathrm{m})\end{array}$ & $\begin{array}{r}\text { Surface } T \\
(\mathrm{~K})\end{array}$ & $\begin{array}{r}\downarrow \text { SWR surface } \\
\left(\mathrm{W} / \mathrm{m}^{2}\right)\end{array}$ & $\begin{array}{r}\uparrow \text { SWR top } \\
\left(\mathrm{W} / \mathrm{m}^{2}\right)\end{array}$ & $\begin{array}{r}T \text { at } 10 \mathrm{~m} \\
(\mathrm{~K})\end{array}$ \\
\hline Aero_load_BCsurf & 98.19 & 511.43 & 285.04 & 490.18 & 102.35 & 279.55 \\
Aero_load_noBCsurf & 111.7 & 509.43 & 285.11 & 511.02 & 108.41 & 279.31 \\
Aero_load_BC700 & 105.18 & 494.99 & 284.69 & 491.72 & 101.91 & 279.02 \\
Aero_load_noBC700 & 111.85 & 510.19 & 285.11 & 515.56 & 109.44 & 279.30 \\
Aero_load_BC500 & 105.0 & 474.28 & 284.69 & 494.00 & 102.39 & 279.04 \\
Aero_load_noBC500 & 111.84 & 508.57 & 285.11 & 515.52 & 109.44 & 279.30 \\
Base case & 112.29 & 510.10 & 285.12 & 516.14 & 109.28 & 279.31 \\
\hline
\end{tabular}

Aerosol layers with identical mass mixing ratios are initialised between $500-950$ and $700-1150 \mathrm{~m}$ to examine the impact of the altitude of the aerosol layer for aerosols above the PBL. The higher aerosol layer (700-1150 m) has less of an impact on PBL height than simulations with the lower aerosol layer (500-950 m). For example, Table 6 shows that case Aero_load_BC500 reduces maximum PBL height by $6.7 \%$ compared to the base case, whereas case Aero_load_BC700 only reduces maximum PBL height by $2.96 \%$. When there are aerosols at $500 \mathrm{~m}$, aerosols can become entrained into the upper PBL, as the PBL develops. This results in a strong heating at the top of and above the PBL, causing a larger decrease in PBL height compared to when the aerosol layer exists higher aloft. Figure 6 shows the potential temperature lapse rate throughout the day for each of the aerosol layers. This shows the inversion for including the aerosol layer at $500 \mathrm{~m}$ is much stronger than for the $700 \mathrm{~m}$ aerosol layer. This causes the larger suppression of PBL development observed under these conditions.

\subsection{Case Met-varied initial meteorological conditions}

In these simulations we examined the sensitivity of BC surface heating on turbulent dynamics to different initial meteorological conditions. Specifically, we assessed whether BC at the surface can cause heating to a large enough extent to overcome the temperature inversion and enhance PBL development, under different initial conditions. On the 2 December, simulations with no aerosols (Met_0212_noaero) show a temperature inversion above PBL top (400-800 m) of $\sim 4 \mathrm{~K}$ at 14:00 LST, compared to $\sim 7 \mathrm{~K}$ on 3 December $(500$ $900 \mathrm{~m}$ ) (Fig. 7). Consequently, including BC at the surface shows a larger enhancement in turbulence for 2 December, when the initial temperature inversion is lower. In this case, 

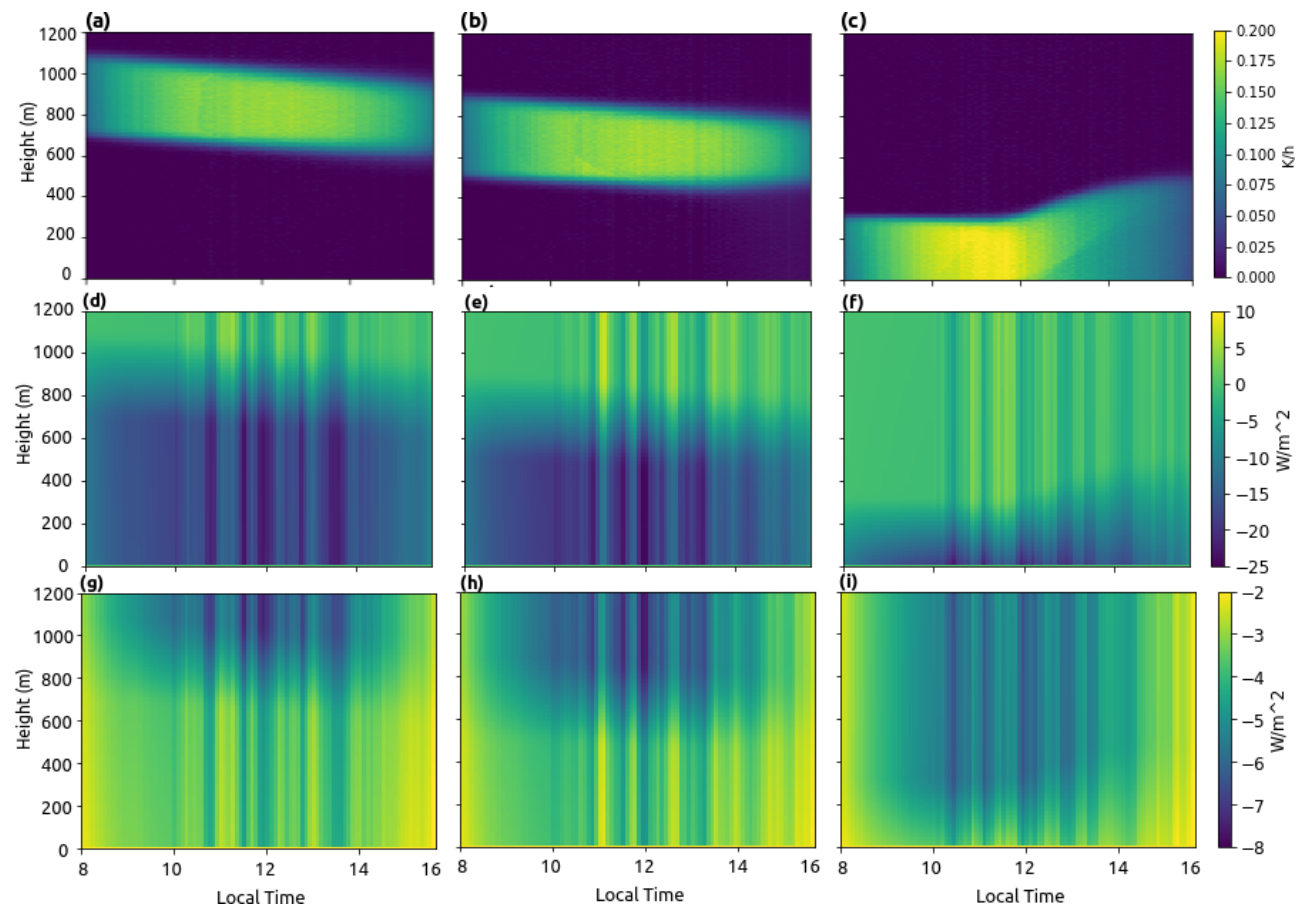

Figure 5. SW heating rate (a-c), loss in downwelling (d-f) and upwelling (g-i) SW radiation due to BC inclusion in the aerosol layer. All plots are normalised against no BC simulations (BC in the aerosol layer - no BC in the aerosol layer) for Aero_load_BC700 (a, d, g), Aero_load_BC500 (b, e, h) and Aero_load_BCsurf $(\mathbf{c}, \mathbf{f}, \mathbf{i})$ simulations.
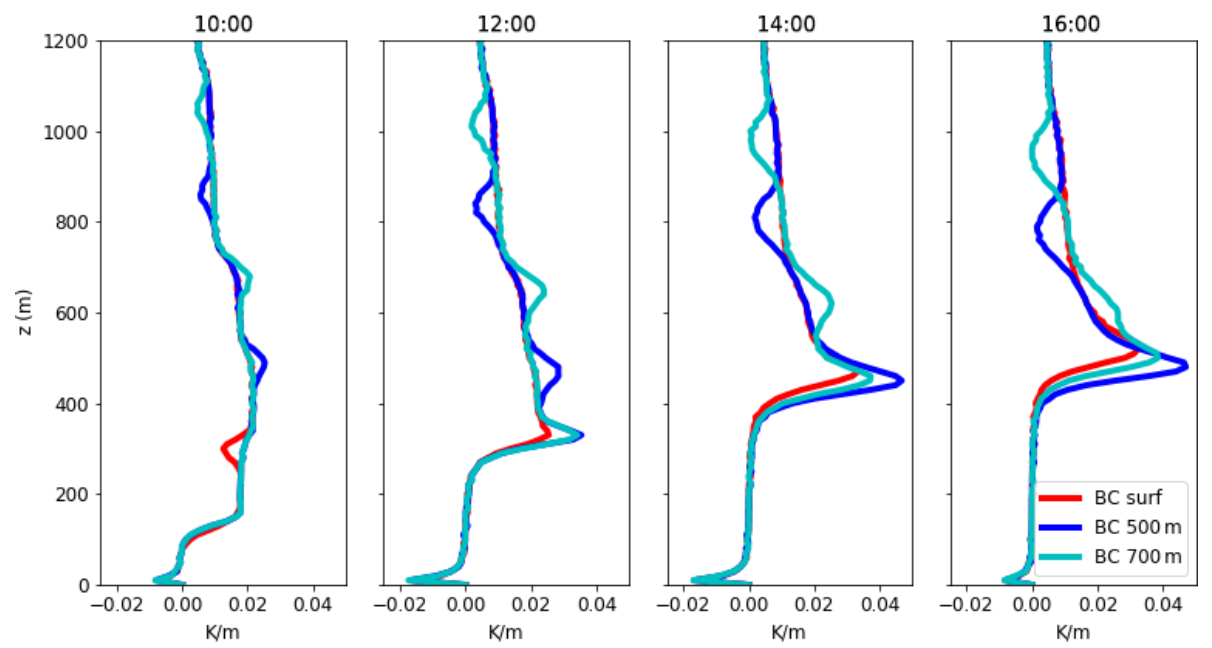

Figure 6. Potential temperature lapse rate for simulations on 3 December at 10:00, 12:00, 14:00 and 16:00 for Aero_load_BCsurf (red), Aero_load_BC500 (blue) and Aero_load_BC700 (cyan) simulations.

$\mathrm{BC}$ at the surface causes a $5 \%$ increase in PBL height, increasing turbulent kinetic energy (TKE) and minimising the decrease in sensible heat flux. This is despite the change in SW downwelling and upwelling radiation being similar for both days (Fig. 8).

Due to the variation in initial meteorological conditions such as humidity, temperature and wind (Fig. 3), it is difficult to ascertain whether the difference in PBL develop- ment caused by BC surface heating is a direct impact of the strength of the temperature inversion. However, it is clear that at least for the case of $\mathrm{BC}$ within the PBL, meteorological conditions affect the magnitude of surface heating on PBL development. These results highlight the susceptibility of the aerosol-PBL feedback to initial conditions as has been outlined in previous work by Slater et al. $(2020,2021)$. In both cases, the $\mathrm{BC}$ concentrations cause a heating rate of $0.2 \mathrm{~K} / \mathrm{h}$ 

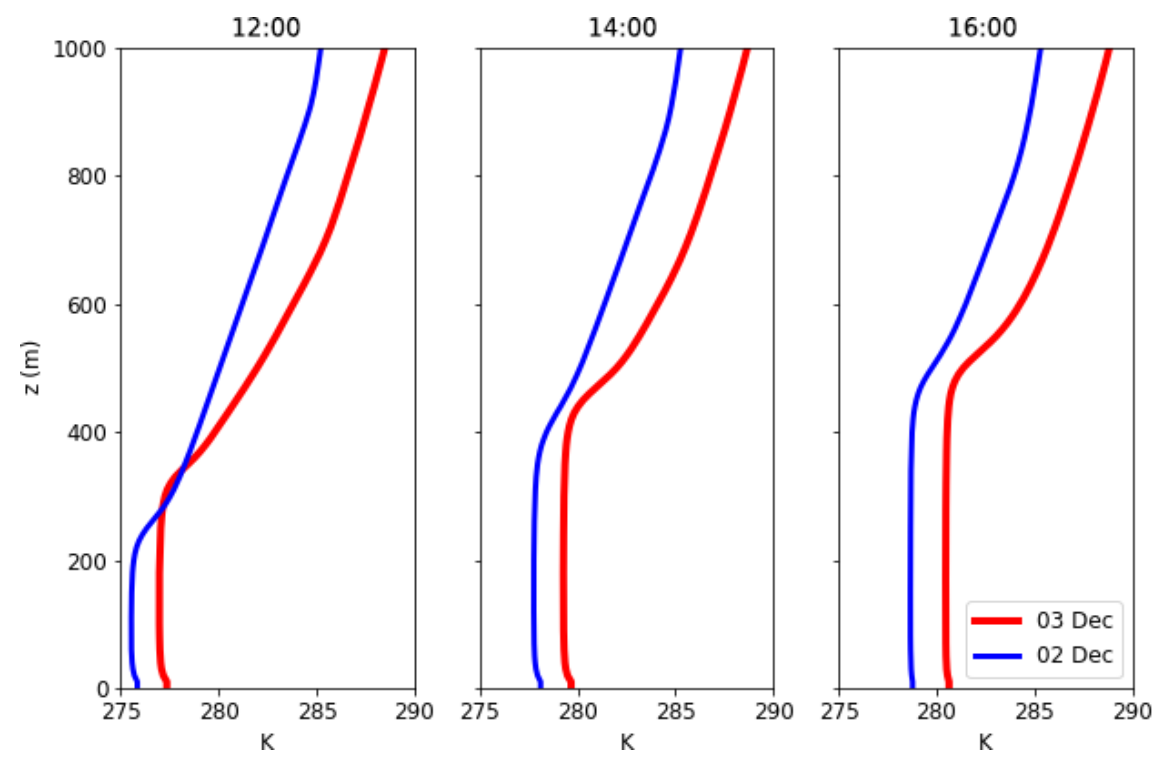

Figure 7. Potential temperature profiles for Met_0312_noaero simulations (red lines) and Met_0212_noaero (blue lines) at 12:00, 14:00 and 16:00 LST.
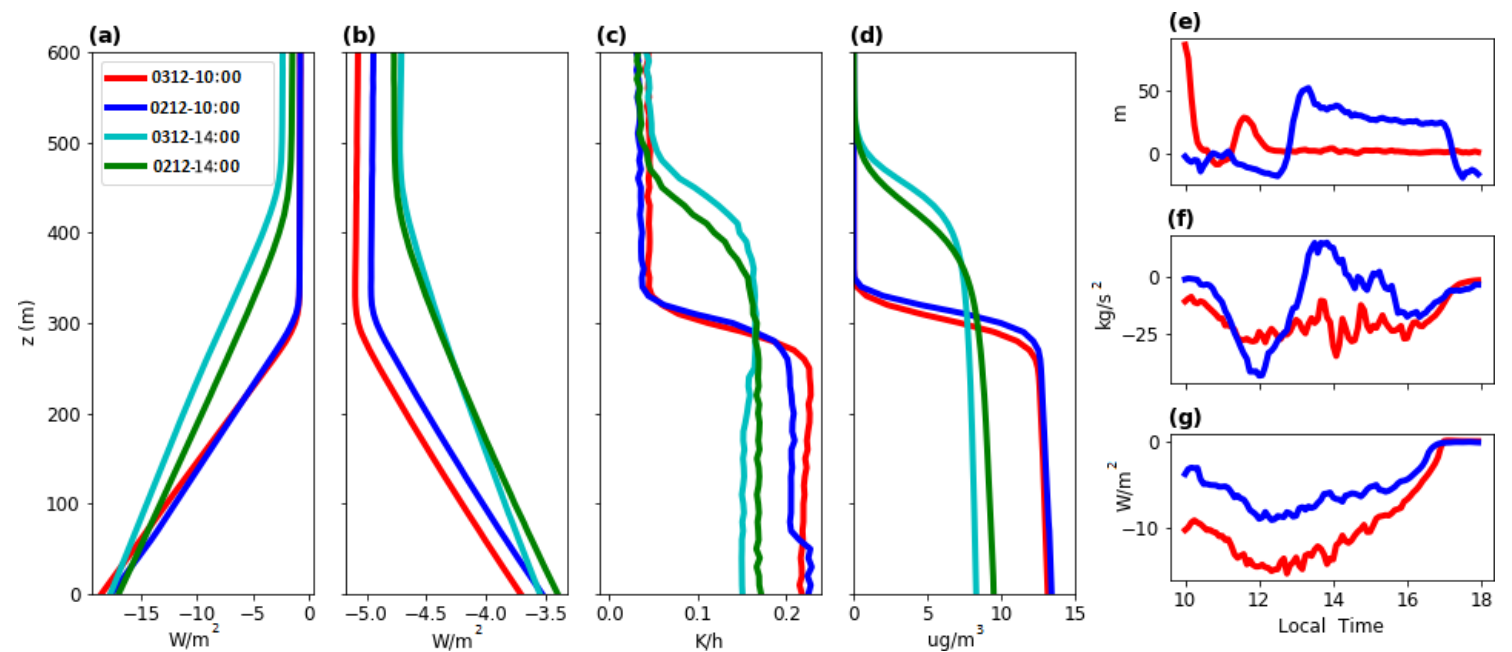

Figure 8. Change (surface aerosol - no aerosols) in (a) downwelling and (b) upwelling SW radiation, (c) SW heating rate and (d) BC concentrations for simulations on 3 December (red and cyan) and 2 December (blue and green) at 10:00 (red and blue) and 14:00 (cyan and green). (e-g) Change (surface aerosol - no aerosols) in (e) PBL height, (f) vertical integral of turbulent kinetic energy (TKE) and (g) sensible heat flux for 3 December (red) and 2 December (blue).

at the surface, which leads to increases in the surface air temperature. Although there is increased turbulence caused by $\mathrm{BC}$ heating on 2 December, the level of heating within and at the top of the PBL is not enough to overcome the strong temperature inversion and the stagnation caused by aerosol-PBL feedback. Consequently, BC heating within the PBL under these conditions will be unlikely to promote haze dissipation due to the strength of the temperature inversion.

Figure 9 shows the potential temperature lapse rate at 12:00, 14:00 and 16:00 for simulations with no aerosols and with BC at the surface for 2 and 3 December. This shows
$\mathrm{BC}$ at the surface reduces the temperature inversion at $\mathrm{PBL}$ top in both cases. Furthermore, at 14:00 the PBL top is higher on 2 December for simulations including $\mathrm{BC}$ at the surface (Met_0212_aero). Here, compared to 3 December (Met_0312_aero), the heating within the PBL and at PBL top appears to be almost strong enough to break the temperature inversion at PBL top and enhance PBL development. As can be seen in Fig. 8d, the aerosol layer becomes vertically mixed throughout the day as the PBL develops. These results show that under conditions with a weaker temperature inversion, $\mathrm{BC}$ heating at the surface enhances turbulent mixing to 

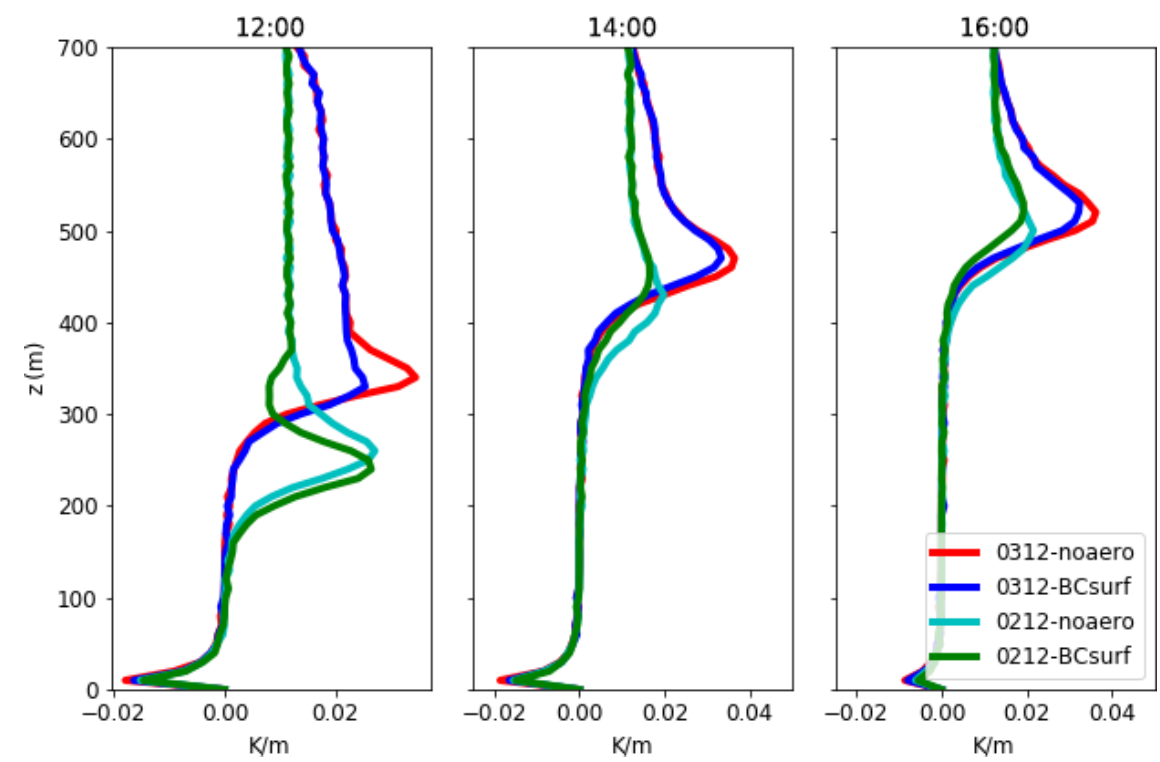

Figure 9. Potential temperature lapse rate at 12:00, 14:00 and 16:00 for simulations with surface aerosols (blue and green) and no aerosols (red and cyan) on 2 December (cyan and green) and 3 December (red and blue).

increase PBL development. If the heating caused by $\mathrm{BC}$ at the surface is strong enough, or under conditions where the temperature inversion is weaker, this may allow for $\mathrm{BC}$ to become vertically mixed to high levels. When the PBL collapses overnight, this leads to $\mathrm{BC}$ being present above the PBL, which may enhance atmospheric stagnation and enhance the intensity of pollution events.

\subsection{Case BC_load - vertically varied BC layers}

Section 3.1 shows the aerosol radiative forcing and perturbations due to $\mathrm{BC}$ are higher than the scattering effect of other aerosols. However, the case Aero_load only identifies the effect of either aerosol concentrations within or above the PBL, where they can exist both within and above the PBL for several reasons. Here, we examine the idea of fully reducing $\mathrm{BC}$ at the surface as a proxy for decreasing $\mathrm{BC}$ emissions locally, where other species are still present, so, for example, targeting sources of BC, such as biomass burning without tackling other sources of inorganic aerosols or volatile gases. $\mathrm{BC}$ aloft is considered to be brought into Beijing through regional transport or entrainment from a polluted residual layer. A study by Ferrero et al. (2014) suggested that the impact of local BC emissions will heat the PBL and lead to pollutant dissipation through promoting atmospheric buoyant turbulence. Results from Sect. 3.1 and 3.2 show the reasonably low impact of $\mathrm{BC}$ at the surface in enhancing PBL development, compared to the suppression caused by the $\mathrm{BC}$ layer at PBL top. Furthermore, if BC from the surface gets mixed into the residual layer, it will negatively impact turbulent mixing the next day. This section looks at including
$\mathrm{BC}$ and other aerosols both within and above the PBL and changing the relative $\mathrm{BC}$ concentration in the column.

In this section, we include aerosols throughout the column and varied the fractional aerosol composition to have BC (BC_load_full) and no BC (BC_load_noBC) throughout the profile and BC above $500 \mathrm{~m}$ (BC_load_500) and $1000 \mathrm{~m}$ (BC_load_1000) (Fig. 4). Our results show that including $\mathrm{BC}$ both within and above the PBL causes a large reduction in PBL height (17\%) compared to no BC (Table 7). In Sect. 3.1 and 3.2 simulations with $\mathrm{BC}$ have a slightly higher PBL height compared to those without (Table 3). Therefore, the decrease in PBL height for these simulations (BC within and above the PBL) indicates that the potential enhancement in turbulence by BC within the PBL (as seen in Sect. 3.1 and 3.2) is eclipsed by the effect of BC above the PBL, which acts strongly to prevent PBL development through the day. This is likely due to the low level of SWR available for BC heating at the surface in the full column BC simulations, due to absorption by $\mathrm{BC}$ at higher altitudes.

Table 7 shows that including $\mathrm{BC}$ has a significant impact on reducing SW downwelling and upwelling radiation, which consequently feeds back and reduces surface temperature and sensible heat flux. Simulations including BC across the entire column (BC_load_full) show the largest decrease in downwelling and upwelling SW radiation, due to the overall larger columnar concentration of BC. Including BC at the surface (BC_load_full)) leads to higher air temperature at $10 \mathrm{~m}$ compared to simulations with BC aloft (BC_load_500 and BC_load_1000) only but lower air temperature at $10 \mathrm{~m}$ than not including BC at the surface (BC_load_noBC). This is likely due to $\mathrm{BC}$ throughout the column absorbing radiation, which leads to heating but also reduces the amount of 
Table 7. Maximum sensible heat flux (SHF), planetary boundary layer (PBL) height (taken as the height with the largest gradient in $\theta$ ), surface temperature $(T)$, downwelling shortwave radiation ( $\downarrow$ SWR) at the surface, upwelling shortwave radiation ( $\uparrow$ SWR) at model top $(1800 \mathrm{~m})$ and air temperature $(T)$ at $10 \mathrm{~m}$. For including aerosols throughout the column but changing the composition for BC_load_1000, BC_load_500, BC_load_full and BC_load_noBC simulations. Values are the maximum between 12:00 and 16:00 local standard time (LST).

\begin{tabular}{|c|c|c|c|c|c|c|}
\hline & $\mathrm{SHF}\left(\mathrm{W} / \mathrm{m}^{2}\right)$ & PBL Height (m) & Surface $T(\mathrm{~K})$ & $\downarrow \mathrm{SWR}$ surface $\left(\mathrm{W} / \mathrm{m}^{2}\right)$ & $\uparrow \mathrm{SWR}$ top $\left(\mathrm{W} / \mathrm{m}^{2}\right)$ & $T$ at $10 \mathrm{~m}(\mathrm{~K})$ \\
\hline BC_load_1000 & 98.40 & 482.84 & 284.43 & 479.90 & 98.42 & 278.85 \\
\hline BC_load_500 & 98.42 & 423.51 & 283.78 & 455.60 & 91.22 & 278.85 \\
\hline BC_load_full & 84.78 & 419.52 & 283.85 & 432.00 & 84.77 & 279.06 \\
\hline BC_load_noBC & 111.03 & 507.39 & 285.10 & 503.79 & 107.90 & 279.29 \\
\hline
\end{tabular}

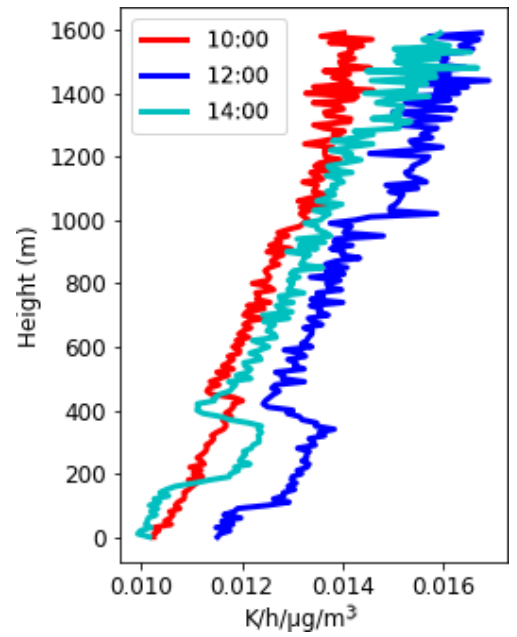

Figure 10. SW heating rate per unit mass of $\mathrm{BC}$ at 10:00, 12:00 and 14:00 on 3 December for simulations with BC throughout the column.

SW radiation reaching the air at the surface, consequently reducing surface air temperature. This work shows that any increase in PBL height due to $\mathrm{BC}$ at the surface is outweighed compared to the stronger impact of $\mathrm{BC}$ above and at PBL top (BC_load_500), which results in the largest decrease in PBL height for simulation with BC across the column (BC_load_full).

Figure 10 shows the $\mathrm{BC}$ heating rate per unit mass of $\mathrm{BC}$, taken as the heating rate for $\mathrm{BC} \_$load_full $-\mathrm{BC} \_$load_noBC simulations. This shows the heating rate per unit mass of $\mathrm{BC}$ increases with height as suggested by Wang et al. (2018). Firstly, we see a strong heating effect increasing up to the bottom of the PBL with a decrease in heating rate across the PBL and a further constant increase above the PBL. The larger heating rate of $\mathrm{BC}$ at higher altitudes is thought to be due to the higher incident radiation available for $\mathrm{BC}$ absorption. Consequently, the heating caused by $\mathrm{BC}$ in the atmosphere and the effect on PBL development will be dependent on the altitude of the BC layer as well as the total BC within the aerosol column. This may be important when examining the impact of BC within the PBL as if BC also exists aloft, as there will be less $\mathrm{SW}$ radiation reaching the surface due to
$\mathrm{BC}$ at higher altitudes, and, consequently, as shown here, $\mathrm{BC}$ heating in the lower layers will be smaller.

\section{Discussion}

The results here show that $\mathrm{BC}$ causes heating in the atmosphere and that absorption of solar radiation by $\mathrm{BC}$ has a larger impact on the temperature profile of the PBL compared to the effect of scattering aerosols. Specifically, BC can cause surface cooling through reducing SW radiation reaching the surface. In this study, $\mathrm{BC}$ causes heating in the aerosol layer at a rate of around $0.01-0.016 \mathrm{~K} / \mathrm{h}^{-1} / \mu \mathrm{g} \mathrm{m} \mathrm{m}^{-3}$ of BC (Fig. 10), which is similar to that proposed by Ding et al. (2016) and Wang et al. (2018). For the concentrations used in this study, this leads to an overall heating of around $0.2 \mathrm{~K} / \mathrm{h}$ or $1-1.6 \mathrm{~K} / \mathrm{d}$, showing the potential impacts of $\mathrm{BC}$ on climate through warming the atmosphere. Furthermore, this work directly investigates the impact of $\mathrm{BC}$ altitude on the layer, where $\mathrm{BC}$ is considered to be the only absorbing aerosol.

From examining the potential temperature lapse rate, we can see that $\mathrm{BC}$ at $500 \mathrm{~m}$ has a larger impact on reducing the temperature inversion at PBL top compared to simulations with $\mathrm{BC}$ at $700 \mathrm{~m}$. This suggests that the absorbing layer has the most impact when it exists at PBL top $(500 \mathrm{~m}$ in these case studies). Furthermore, throughout the day the aerosol layer becomes entrained into the PBL as it develops. When aerosols are included throughout the column, we observe an enhanced effect on PBL suppression, with a decrease of $16 \%$ compared to not including BC and only a slightly lower impact than having $\mathrm{BC}$ throughout the entire column (Sect. 3.3). When there are aerosols throughout the column, BC at the surface will receive less SW downwelling radiation compared to $\mathrm{BC}$ aloft due to the interactions of the aerosols above it, preventing SW downwelling reaching lower levels. Consequently, there will be more SW radiation available for the $\mathrm{BC}$ aloft to absorb and heat the atmosphere. Figure 10 shows that the heating rate per unit mass of BC is higher aloft than at the surface, meaning that the impact of PBL suppression by $\mathrm{BC}$ aloft will often negate the impact of surface $\mathrm{BC}$ promoting PBL development. 
At the surface, including BC increases air temperature but decreases sensible heat flux through reducing the amount of $\mathrm{SW}$ radiation reaching the surface. We examine the impact of $\mathrm{BC}$ at the surface for a case study including the 2 and 3 December 2016 and find that the magnitude of the impact is different on each day. This highlights the potential for initial meteorological conditions to influence the effect of BC on the aerosol-PBL feedback effect. In Sect. 3.1 and 3.2, we identify that the strong temperature inversion at PBL top throughout the day on the 3 December prevents $\mathrm{BC}$ heating from enhancing PBL development. The impact of $\mathrm{BC}$ within the PBL on PBL height in our simulation is small ( $0.26 \%$ increase), compared to a $4 \%-6 \%$ increase suggested by Wang et al. (2018), despite the heating rates due to BC being similar. We believe this is due to the strength of the temperature inversion caused by the initial conditions on 3 December (Fig. 3a). A temperature inversion, often known as the capping inversion, is the sharp increase in temperature at PBL top and can be enhanced or diminished by aerosol-radiation interactions (Stull, 2015). Warming of the air at PBL top by BC can reduce the difference in temperature between the PBL and free atmosphere, reducing the temperature inversion and making it easier for air parcels to move upwards. In some cases, this will increase PBL height. In the work by Wang et al. (2018), the temperature inversion at PBL top to $400 \mathrm{~m}$ above PBL top at 14:00 LST without aerosol inclusion is $\sim 3 \mathrm{~K}$; in our case it is $\sim 7 \mathrm{~K}$.

Temperature inversions and stable conditions are frequently brought about by synoptic condition changes in wintertime Beijing and are strengthened over the pollution episode as aerosols cool the surface. Wang et al. (2019) examined the causes of the pollution episode examined in this work (1-4 December 2016) to understand the influences of synoptic-scale meteorology and aerosol-PBL feedback effect on the pollution episode. They suggest the strong temperature inversion on the 3 December is due to both the impact of synoptic conditions and the aerosol-PBL feedback from the previous day causing surface cooling. Overall, we find that surface BC causes warming and enhances turbulence. This increases PBL height by $0.26 \%$ on 3 December due to the strong initial temperature inversion $(7.0 \mathrm{~K}$ in the lowest $500 \mathrm{~m}$ at 10:00) but increases PBL height by $5 \%$ on 2 December due to the weaker temperature inversion $(4.2 \mathrm{~K}$ in the lowest $500 \mathrm{~m}$ at 10:00). However in these conditions, the heating rate is still not enough to fully weaken the strong temperature inversion (Fig. 9).

A recent study by Ma et al. (2020) utilises an LES model to investigate the impacts of the altitude of absorbing and scattering aerosol layers on planetary boundary layer height, although, in their work, they do not specifically treat the aerosol population but focus on changing the aerosol optical depth and aerosol optical properties directly. Their work agrees with the work published here, to show that absorbing aerosols above the PBL will suppress turbulence and PBL growth due to the so-called dome effect. Their results also show an increase in PBL height due to absorbing aerosols at the surface promoting turbulent motion, which they term the "stove effect". In contrast to the work presented here, their work shows a much greater increase in PBL height due to absorbing aerosols within the PBL; however, the $\mathrm{PM}_{2.5}$ concentrations over the period investigated by Ma et al. (2020) are much lower than in this work. Similarly, the maximum PBL height in that work (around $1000 \mathrm{~m}$ ) is much higher than in our work. Consequently, it is likely that the specific meteorological conditions are different in Ma et al. (2020) and this study and that, as highlighted in Sect. 3.2 of this paper, this has a significant impact on the ability of absorbing aerosols to increase PBL height or the magnitude of the stove effect.

This work shows that BC heating may significantly increase the PBL height, specifically under conditions with weaker capping inversions. However, surface BC only has a small effect on enhancing PBL development under strongly stagnant meteorological conditions. It is therefore unlikely that under polluted conditions in wintertime Beijing BC heating at the surface will strongly impact the aerosol-PBL feedback loop to lessen the severity of pollution episodes. It may be, however, that under certain conditions when the temperature inversion is low, the heating of BC impacts PBL development and may enhance the recovery phase of a pollution event, though we have not focused on this aspect in this paper. We calculate a heating rate of around $0.2 \mathrm{~K} / \mathrm{h}$, and assuming a daytime heating in Beijing winter of $8 \mathrm{~h}$, the heating at PBL top could reach around $1.6 \mathrm{~K}$, which is too small to change temperature inversions which are common during haze episodes and are typically 4-7 K. However, in cases with weaker temperature inversions $(1-2 \mathrm{~K})$, the heating caused by surface BC may be strong enough to cause modifications to the PBL development. This allows for increased vertical mixing of aerosols and may allow for $\mathrm{BC}$ to be mixed higher into the PBL, when cooling of the surface overnight results in a very stable shallow nocturnal boundary layer forming, which could leave some of the polluted aerosol layer aloft. The next day this polluted absorbing layer will heat the layer above the PBL, thus changing the temperature profile of the PBL to reduce buoyancy. This reduces PBL height and enhances the aerosol-PBL feedback to increase surface $\mathrm{PM}_{2.5}$ and intensify pollution episodes (Fig. 11). Our results show that $\mathrm{BC}$ above the $\mathrm{PBL}$ has more impact than $\mathrm{BC}$ below, and consequently if $\mathrm{BC}$ is present throughout the column, the effect of suppressing turbulent motion by $\mathrm{BC}$ is greater than the enhancement effect.

In performing simulations including $\mathrm{BC}$ throughout the column (case BC_load), this work can directly show that the impact of $\mathrm{BC}$ heating within the PBL is negated by the stronger impact of $\mathrm{BC}$ aloft, which absorbs a significant proportion of SW solar radiation. This means there is less absorption of SW radiation by $\mathrm{BC}$ within the $\mathrm{PBL}$ or at lower altitudes. This work therefore adds to the studies by Ding et al. (2016), which only show the effect of BC at and above PBL top, and Wang et al. (2018), which examine the impact 


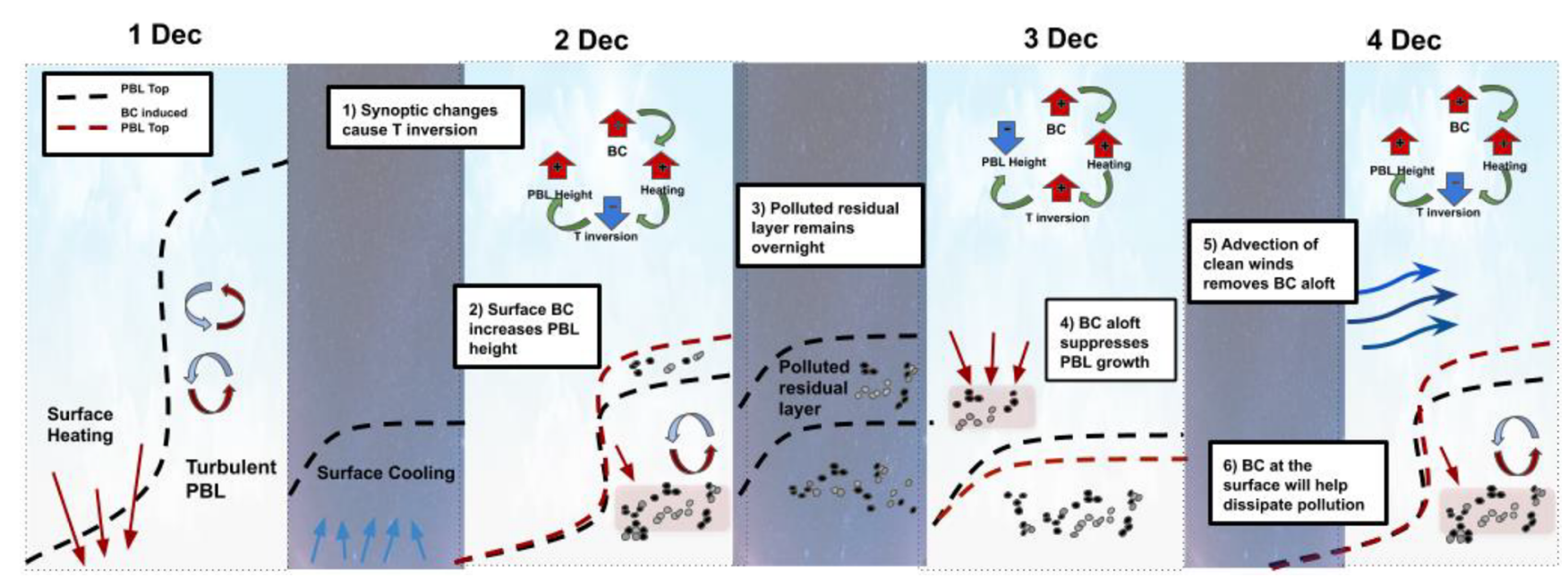

Figure 11. Schematic to show the potential impact of BC on a Beijing haze episode which occurred between 1 and 4 December 2016, where both the onset and dissipation of the pollution episode are brought about by changing synoptic patterns. The dashed black lines indicate PBL top, with the dashed red lines indicating the change caused by BC interactions and the type of impact that is dependent on the altitude of the BC layer.

of BC layers at different altitudes separately rather than the effect of multiple BC layers. Our work also shows the importance of initial conditions on the BC surface heating effect as outlined for aerosols in general by Slater et al. $(2020,2021)$. This is important as these conditions change over the course of the haze episode, with PBL height found to decrease by as much as $50 \%$ due to synoptic influences alone (Wang et al., 2019; Slater et al., 2021). In the work by Wang et al. (2018), only one set of meteorological conditions are examined, which limits the applicability of the results to periods with similar conditions, while our work shows that conditions on 2 December lead to a PBL enhancement of $5 \%$, compared to $0.4 \%$ on 3 December.

\subsection{Limitations and novelty of this study}

Using a coupled aerosol-radiation LES model in this study allowed for direct investigation and quantification of the impact of absorbing aerosols on boundary layer dynamics. There is an array of benefits of using a high-resolution model which directly calculates rather than parameterises turbulent fluxes for the investigation of heavy pollution episodes. As previously highlighted in this paper, the importance of aerosol-boundary layer feedbacks on heavy pollution episodes, particularly in the megacity of Beijing, has been made clear in the literature over the last decade. Primarily, these studies have utilised measurements of aerosol properties alongside measurements of boundary layer dynamics and meteorology to infer the impact and relationship between aerosols and boundary layer dynamics. Modelling studies of the aerosol-boundary layer feedback mechanism have mostly utilised regional models such as WRFCHEM, which do not directly resolve turbulent flows. There- fore, the work presented here showcases a novel methodology for investigation of the contrasting impact of absorbing aerosols on boundary layer dynamics and the usefulness of employing such high-resolution eddy-resolving coupled aerosol-dynamic models to examine physical processes and interactions which can severely influence pollution episodes.

However, applying the idealised model setup to a polluted megacity has limitations. Not being able to fully account for changes in synoptic conditions or understand the impact of regional transport of aerosols on the pollution episodes is a major limitation of the work presented here. Similarly, this work does not look at the impact of secondary aerosol formation which has been found to be a major factor in the rapid increase in $\mathrm{PM}_{2.5}$ concentrations during Beijing haze episodes. Specifically, with regards to the effect of black carbon on aerosol-boundary layer feedback, a current limitation of the work presented here is that it does not account for the absorption enhancement of black carbon by scattering aerosols through the lensing effect (Liu et al., 2017). Furthermore, in this work we consider the only absorbing aerosol to be black carbon, while brown carbon $(\mathrm{BrC})$ has been found to be an important absorber of radiation in several polluted megacities. Although $\mathrm{BrC}$ is not as strong an absorber of radiation as black carbon, its presence in high concentrations in polluted urban environments means its impact on these feedbacks should not be discounted (Cheng et al., 2016; Xie et al., 2019). There is scope within UCLALES-SALSA to change the refractive indices and mixing type to reflect some features related to changes in absorption. However, in this work, for simplicity and to allow for the ability to isolate different effects, these were not considered. 


\subsection{A mechanism for the impact of $\mathrm{BC}$ on Beijing pollution episodes}

Combining all the results presented in this paper as well as other research by Wang et al. (2018) and Ding et al. (2016), here we detail a potential mechanism for the influence of $\mathrm{BC}$ on air pollution episodes in Beijing (Fig. 11). Although this mechanism has not been fully tested in this work due to computational cost, we hypothesise that locally emitted BC which heats the PBL could promote PBL development (Sect. 3.2), resulting in the $\mathrm{BC}$ becoming well mixed through the PBL. When the nocturnal boundary layer forms, the BC will remain in the residual layer overnight and exist above the PBL the next day. This would then suppress PBL development as shown in Sect. 3.1 and 3.3 of this work and in the work by Ding et al. (2016). However, if synoptic conditions on the next day changed to weaken the temperature inversion and the PBL developed, as observed during this haze episode by Wang et al. (2019), the BC aloft could become entrained into the PBL to heat the surface layer and help promote buoyant turbulence and the dissipation of pollutants (Fig. 11). This mechanism could have strong influences for policy, and we would therefore recommend that further research be performed to directly investigate the mechanism and its potential to influence the severity and longevity of haze episodes.

\section{Conclusions}

Overall, this work showcases and quantifies the various contrasting impacts that $\mathrm{BC}$ can play in the aerosol-PBL feedback and consequently the enhancement or dissipation of pollution episodes over Beijing. We also show that there are several factors which may influence both the magnitude and type of effect, including the altitude of the aerosol layers and initial meteorological conditions.

From this work, we suggest the following: (a) the impact of BC aloft on PBL suppression is dependent on the altitude of the aerosol layer in relation to PBL height; (b) BC surface heating impact on PBL development is dependent on the strength of the initial temperature inversion; and (c) when $\mathrm{BC}$ is present throughout the column, the strong interactions aloft eclipse the impact of BC surface heating. Overall, we show that $\mathrm{BC}$ causes heating at a rate of $0.15-0.2 \mathrm{~K} / \mathrm{h}$ during the daytime, which suggests that $\mathrm{BC}$ direct radiative forcing has implications for climate, through warming the atmosphere. In terms of the local effect of BC on the aerosol-PBL feedback, BC high above the PBL has little impact on PBL development, while $\mathrm{BC}$ just above the PBL suppresses PBL growth. Furthermore, controlling regional emissions of $\mathrm{BC}$ will significantly reduce the amount of $\mathrm{BC}$ aloft, which may reduce the severity of pollution episodes associated with atmospheric stagnation in Beijing.

Here, as shown in Fig. 11, we propose a novel mechanism on how BC may impact pollution episodes in Beijing:
1. At the beginning of the haze episode, synoptic conditions lead to a temperature inversion over Beijing and light winds at the surface, allowing for pollution accumulation in a shallow PBL.

2. BC emitted locally and regionally will be trapped in the surface layer, and our results show that this will heat the air at the surface.

3. If the temperature inversion is weak $(1-3 \mathrm{~K})$, then this will cause sufficient heating at the aerosol loads often found in Beijing to break the temperature inversion at PBL top and enhance vertical mixing to move BC higher in the layer.

4. As the PBL collapses overnight, BC concentrations will exist in residual layers above the nocturnal temperature inversion close to the surface.

5. The following day, these $\mathrm{BC}$ layers will heat the air above the PBL and due to the higher SW downwelling radiation aloft, will outweigh the effect of surface $\mathrm{BC}$ heating to enhance stability in the column and cause the suppression of the PBL. This exacerbates the pollution event on subsequent days.

6. When changes in synoptic conditions cause the pressure system to move away and upper level winds advect in cleaner air, the suppression of the PBL by BC heating diminishes. High $\mathrm{BC}$ concentrations in the PBL remain, but as we have shown, these act to heat the surface and will aid the recovery of the PBL and lessen impact of pollution by promoting mixing at PBL top as the temperature inversion strength weakens (Fig. 11).

Code and data availability. The model code used for this study is open-access and available at https://github.com/ UCLALES-SALSA (last access: 15 October 2019). All data used for comparison were taken as part of the APHH Beijing campaign and are available upon request from the author and acknowledged colleagues.

Author contributions. The idea for the study was conceived by JS, GM and HC. All model simulations were performed by JS with the assistance of JT and SR. JS wrote the paper with input from HC, GM, JT and SR. All co-authors discussed the results and commented on the manuscript.

Competing interests. The contact author has declared that neither they nor their co-authors have any competing interests.

Disclaimer. Publisher's note: Copernicus Publications remains neutral with regard to jurisdictional claims in published maps and institutional affiliations. 
Acknowledgements. Model simulations were carried out on the ARCHER UK National Supercomputing Service (http://www. archer.ac.uk, last access: 31 March 2020). We gratefully acknowledge Yele Sun's group and Pingqing Fu's group at IAP for aerosol composition data and tower meteorological data, respectively, as well as Zifa Wang's group at Peking University for aerosol size data and Eiko Nemitz at CEH Edinburgh for heat flux data.

Financial support. This research has been supported by the National Centre for Atmospheric Science (NCAS). Jessica Slater, Hugh Coe and Gordon McFiggans were part of the APHH Beijing AIRPRO programme (grant no. NE/N00695X/1). Sami Romakkaniemi and Juha Tonttila were supported by the Academy of Finland (grant no. 283031) and Horizon 2020 Research and Innovation programme (grant no. 821205).

Review statement. This paper was edited by Toshihiko Takemura and reviewed by Mona Kurppa and one anonymous referee.

\section{References}

Ács, F., Mihailović, D. T., and Rajković, B.: A Coupled Soil Moisture and Surface Temperature Prediction Model, J. Appl. Meteorol., 30, 812-822, https://doi.org/https://doi.org/10.1175/15200450(1991)030<0812:ACSMAS>2.0.CO;2, 1991.

Bond, T. C. and Bergstrom, R. W.: Light absorption by carbonaceous particles: An investigative review, Aerosol Sci. Technol., 40, 27-67, https://doi.org/10.1080/02786820500421521, 2006.

Bond, T. C., Doherty, S. J., Fahey, D. W., Forster, P. M., Berntsen, T., Deangelo, B. J., Flanner, M. G., Ghan, S., Kärcher, B., Koch, D., Kinne, S., Kondo, Y., Quinn, P. K., Sarofim, M. C., Schultz, M. G., Schulz, M., Venkataraman, C., Zhang, H., Zhang, S., Bellouin, N., Guttikunda, S. K., Hopke, P. K., Jacobson, M. Z., Kaiser, J. W., Klimont, Z., Lohmann, U., Schwarz, J. P., Shindell, D., Storelvmo, T., Warren, S. G., and Zender, C. S.: Bounding the role of black carbon in the climate system: A scientific assessment, J. Geophys. Res.-Atmos., 118, 5380-5552, https://doi.org/10.1002/jgrd.50171, 2013.

Chan, C. K. and Yao, X.: Air pollution in mega cities in China, Atmos. Environ., 42, 1-42, https://doi.org/10.1016/j.atmosenv.2007.09.003, 2008.

Chen, H., Rey, J., Kwong, C., Copes, R., Tu, K., Villeneuve, P. J., Van Donkelaar, A., Hystad, P., Martin, R. V., Murray, B. J., Jessiman, B., Wilton, A. S., Kopp, A., and Burnett, R. T.: Living near major roads and the incidence of dementia, Parkinson's disease, and multiple sclerosis: a population-based cohort study, The Lancet 389, 718-726, https://doi.org/10.1016/S01406736(16)32399-6, 2017.

Cheng, Y., bin He, K., yu Du, Z., Engling, G., meng Liu, J., liang Ma, Y., Zheng, M., and Weber, R. J.: The characteristics of brown carbon aerosol during winter in Beijing, Atmos. Environ., 127, 355-364, https://doi.org/10.1016/j.atmosenv.2015.12.035, 2016.

Ding, A. J., Huang, X., Nie, W., Sun, J. N., Kerminen, V. M., Petäjä, T., Su, H., Cheng, Y. F., Yang, X. Q., Wang, M. H., Chi, X. G., Wang, J. P., Virkkula, A., Guo, W. D., Yuan, J., Wang, S. Y., Zhang, R. J., Wu, Y. F., Song, Y., Zhu, T., Zilitinkevich, S., Kul- mala, M., and Fu, C. B.: Enhanced haze pollution by black carbon in megacities in China, Geophys. Res. Lett., 43, 2873-2879, https://doi.org/10.1002/2016GL067745, 2016.

Ding, Y., Wu, P., Liu, Y., and Song, Y.: Environmental and Dynamic Conditions for the Occurrence of Persistent Haze Events in North China, Engineering, 3, 266-271, https://doi.org/10.1016/J.ENG.2017.01.009, 2017.

Ferrero, L., Castelli, M., Ferrini, B. S., Moscatelli, M., Perrone, M. G., Sangiorgi, G., D’Angelo, L., Rovelli, G., Moroni, B., Scardazza, F., Močnik, G., Bolzacchini, E., Petitta, M., and Cappelletti, D.: Impact of black carbon aerosol over Italian basin valleys: high-resolution measurements along vertical profiles, radiative forcing and heating rate, Atmos. Chem. Phys., 14, 96419664, https://doi.org/10.5194/acp-14-9641-2014, 2014.

$\mathrm{Fu}, \mathrm{H}$. and Chen, J.: Formation, features and controlling strategies of severe haze-fog pollutions in China, Sci. Tot. Environ., 578, 121-138, https://doi.org/10.1016/j.scitotenv.2016.10.201, 2016.

$\mathrm{Fu}, \mathrm{Q}$. and Liou, K. N.: Parameterization of the Radiative Properties of Cirrus Clouds, J. Atmos. Sci., 50, 2008-2025, https://doi.org/10.1175/15200469(1993)050<2008:POTRPO>2.0.CO;2, 1993.

Gao, M., Guttikunda, S. K., Carmichael, G. R., Wang, Y., Liu, Z., Stanier, C. O., Saide, P. E., and Yu, M.: Health impacts and economic losses assessment of the 2013 severe haze event in Beijing area, Sci. Total Environ., 511, 553-561, https://doi.org/10.1016/j.scitotenv.2015.01.005, 2015.

Herbert, R. J., Bellouin, N., Highwood, E. J., and Hill, A. A.: Diurnal cycle of the semi-direct effect from a persistent absorbing aerosol layer over marine stratocumulus in large-eddy simulations, Atmos. Chem. Phys., 20, 1317-1340, https://doi.org/10.5194/acp-20-1317-2020, 2020.

Jacobson, M. Z.: Fundamentals of Atmospheric Modelling, Chapter 9: Radiative Energy Transfer, 273-335, 2005.

Kokkola, H., Korhonen, H., Lehtinen, K. E. J., Makkonen, R., Asmi, A., Järvenoja, S., Anttila, T., Partanen, A.-I., Kulmala, M., Järvinen, H., Laaksonen, A., and Kerminen, V.-M.: SALSA - a Sectional Aerosol module for Large Scale Applications, Atmos. Chem. Phys., 8, 2469-2483, https://doi.org/10.5194/acp-8-24692008, 2008.

Kokkola, H., Kühn, T., Laakso, A., Bergman, T., Lehtinen, K. E. J., Mielonen, T., Arola, A., Stadtler, S., Korhonen, H., Ferrachat, S., Lohmann, U., Neubauer, D., Tegen, I., SiegenthalerLe Drian, C., Schultz, M. G., Bey, I., Stier, P., Daskalakis, N., Heald, C. L., and Romakkaniemi, S.: SALSA2.0: The sectional aerosol module of the aerosol-chemistry-climate model ECHAM6.3.0-HAM2.3-MOZ1.0, Geosci. Model Dev., 11, 3833-3863, https://doi.org/10.5194/gmd-11-3833-2018, 2018.

Lelieveld, J., Evans, J. S., Fnais, M., Giannadaki, D., and Pozzer, A.: The contribution of outdoor air pollution sources to premature mortality on a global scale, Nature, 525, 367-371, https://doi.org/10.1038/nature15371, 2015.

Li, J. and Han, Z.: A modeling study of severe winter haze events in Beijing and its neighboring regions, Atmos. Res., 170, 87-97,house standards, quotation marks https://doi.org/10.1016/j.atmosres.2015.11.009, 2016.

Liu, D., Whitehead, J., Alfarra, M. R., Reyes-Villegas, E., Spracklen, D. V., Reddington, C. L., Kong, S., Williams, P. I., Ting, Y.-C., Haslett, S., Taylor, J. W., Flynn, M. J., Morgan, W. T., McFiggans, G., Coe, H., and Allan, J. D.: 
Black-carbon absorption enhancement in the atmosphere determined by particle mixing state, Nat. Geosci., 10, 184-188, https://doi.org/10.1038/ngeo2901, 2017.

Liu, Q., Ma, T., Olson, M. R., Liu, Y., Zhang, T., Wu, Y., and Schauer, J. J.: Temporal variations of black carbon during haze and non-haze days in Beijing, Sci. Rep., 6, 33331, https://doi.org/10.1038/srep33331, 2016.

Ma, Y., Ye, J., Xin, J., Zhang, W., Vilà-Guerau de Arellano, J., Wang, S., Zhao, D., Dai, L., Ma, Y., Wu, X., Xia, X., Tang, G., Wang, Y., Shen, P., Lei, Y., and Martin, S. T.: The Stove, Dome, and Umbrella Effects of Atmospheric Aerosol on the Development of the Planetary Boundary Layer in Hazy Regions, Geophys. Res. Lett., 47, 1-10, https://doi.org/10.1029/2020GL087373, 2020.

Maalick, Z., Kuhn, T., Korhonen, H., Kokkola, H., Laaksonen, A., and Romakkaniemi, S.: Effect of aerosol concentration and absorbing aerosol on the radiation fog life cycle, Atmos. Environ., 133, 26-33, https://doi.org/10.1016/j.atmosenv.2016.03.018, 2016.

Petäjä, T., Järvi, L., Kerminen, V.-M., Ding, A. J., Sun, J. N., Nie, W., Kujansuu, J., Virkkula, A., Yang, X., Fu, C. B., Zilitinkevich, S., and Kulmala, M.: Enhanced air pollution via aerosol-boundary layer feedback in China., Sci. Rep., 6, 18998, https://doi.org/10.1038/srep18998, 2016.

Ramanathan, V. and Carmichael, G.: Global and regional climate changes due to black carbon, Nat. Geosci., 1, 221-227, https://doi.org/10.1038/ngeo156, 2008.

Slater, J., Tonttila, J., McFiggans, G., Connolly, P., Romakkaniemi, S., Kühn, T., and Coe, H.: Using a coupled large-eddy simulation-aerosol radiation model to investigate urban haze: sensitivity to aerosol loading and meteorological conditions, Atmos. Chem. Phys., 20, 11893-11906, https://doi.org/10.5194/acp-20-11893-2020, 2020.

Slater, J., Tonttila, J., McFiggans, G., Coe, H., Romakkaniemi, S., Sun, Y., Xu, W., Fu, P., and Wang, Z.: Using a coupled LES aerosol-radiation model to investigate the importance of aerosol-boundary layer feedback in a Beijing haze episode, Faraday Discuss., 2021, 173-190, https://doi.org/10.1039/d0fd00085j, 2021.

Streets, D. G., Gupta, S., Waldhoff, S. T., Wang, M. Q., Bond, T. C., and Yiyun, B.: Black carbon emissions in China, Atmos. Environ., 35, 4281-4296, https://doi.org/10.1016/S13522310(01)00179-0, 2001

Stull, R.: Atmospheric Boundary Layer, in: Practical Meteorology: An Algebra-based Survey of Atmospheric Science, 119-158, 2015.

Tonttila, J., Maalick, Z., Raatikainen, T., Kokkola, H., Kühn, T., and Romakkaniemi, S.: UCLALES-SALSA v1.0: a largeeddy model with interactive sectional microphysics for aerosol, clouds and precipitation, Geosci. Model Dev., 10, 169-188, https://doi.org/10.5194/gmd-10-169-2017, 2017.
Tonttila, J., Afzalifar, A., Kokkola, H., Raatikainen, T., Korhonen, H., and Romakkaniemi, S.: Precipitation enhancement in stratocumulus clouds through airborne seeding: sensitivity analysis by UCLALES-SALSA, Atmos. Chem. Phys., 21, 1035-1048, https://doi.org/10.5194/acp-21-1035-2021, 2021.

Wang, L., Liu, J., Gao, Z., Li, Y., Huang, M., Fan, S., Zhang, X., Yang, Y., Miao, S., Zou, H., Sun, Y., Chen, Y., and Yang, T.: Vertical observations of the atmospheric boundary layer structure over Beijing urban area during air pollution episodes, Atmos. Chem. Phys., 19, 6949-6967, https://doi.org/10.5194/acp19-6949-2019, 2019.

Wang, Q., Huang, R. J., Cao, J., Tie, X., Shen, Z., Zhao, S., Han, Y., Li, G., Li, Z., Ni, H., Zhou, Y., Wang, M., Chen, Y., and Su, $\mathrm{X}$.: Contribution of regional transport to the black carbon aerosol during winter haze period in Beijing, Atmos. Environ., 132, $11-$ 18, https://doi.org/10.1016/j.atmosenv.2016.02.031, 2016.

Wang, Z., Huang, X., and Ding, A.: Dome effect of black carbon and its key influencing factors: a one-dimensional modelling study, Atmos. Chem. Phys., 18, 2821-2834, https://doi.org/10.5194/acp-18-2821-2018, 2018.

WHO: Health risks of particulate matter from long-range transboundary air pollution, Pollution Atmospherique, p. 169, ISBN 97892890 42895, 2006.

Xie, C., Xu, W., Wang, J., Wang, Q., Liu, D., Tang, G., Chen, P., Du, W., Zhao, J., Zhang, Y., Zhou, W., Han, T., Bian, Q., Li, J., Fu, P., Wang, Z., Ge, X., Allan, J., Coe, H., and Sun, Y.: Vertical characterization of aerosol optical properties and brown carbon in winter in urban Beijing, China, Atmos. Chem. Phys., 19, 165179, https://doi.org/10.5194/acp-19-165-2019, 2019.

Yang, G., Wang, Y., Zeng, Y., Gao, G. F., Liang, X., Zhou, M., Wan, X., Yu, S., Jiang, Y., Naghavi, M., Vos, T., Wang, H., Lopez, A. D., and Murray, C. J. L.: Rapid health transition in China, 1990-2010: Findings from the Global Burden of disease study 2010, The Lancet, 381, 1987-2015, https://doi.org/10.1016/S0140-6736(13)61097-1, 2013.

Zhao, D., Liu, D., Yu, C., Tian, P., Hu, D., Zhou, W., Ding, S., Hu, K., Sun, Z., Huang, M., Huang, Y., Yang, Y., Wang, F., Sheng, J., Liu, Q., Kong, S., Li, X., He, H., and Ding, D.: Vertical evolution of black carbon characteristics and heating rate during a haze event in Beijing winter, Sci. Tot. Environ., 709, 136251, https://doi.org/10.1016/j.scitotenv.2019.136251, 2020.

Zou, J., Sun, J., Ding, A., Wang, M., Guo, W., and Fu, C.: Observation-based estimation of aerosol-induced reduction of planetary boundary layer height, Adv. Atmos. Sci., 34, 10571068, https://doi.org/10.1007/s00376-016-6259-8, 2017. 